\title{
Comparative interevent time statistics of degassing and seismic activity at Villarrica Volcano (Chile)
}

\author{
Johanna Lehr ${ }^{1}$, Stefan Bredemeyer ${ }^{2,3}$, Wolfgang Rabbel ${ }^{1}$, Martin Thorwart ${ }^{1}$, \\ Luis Franco-Marín ${ }^{4}$ \\ ${ }^{1}$ Kiel University \\ ${ }^{2}$ GEOMAR Helmholtz Centre for Ocean Research Kiel, Kiel, Germany \\ ${ }^{3}$ GFZ German Research Centre for Geosciences, Potsdam, Germany \\ ${ }^{4}$ Observatorio Volcanológico de los Andes del Sur (OVDAS), Servicio Nacional de Geologa y Minera \\ (SERnAGEOMIN), Temuco, Chile
}

\section{Key Points:}

- We compare the statistical distribution of time intervals between of explosive and volcano-tectonic seismic signals and degassing events.

- Normalized distributions of explosions and degassing events are surprisingly similar despite different orders of magnitude of time scales.

- Their interplay was modeled as a renewal process.

\section{Plain Language Summary}

[ enter your Plain Language Summary here or delete this section]

Corresponding author: Johanna Lehr, johanna.lehr@ifg.uni-kiel.de 


\begin{abstract}
It is generally assumed that seismic activity at volcanoes is closely connected to degassing processes. Intuitively, one would therefore expect a good correlation between degassing rates and seismic amplitude. However, both examples and counterexamples of such a correlation exist. In this study on Villarrica volcano (Chile), we pursued a different approach to relate gas flux and volcanic seismicity using 3 months of $\mathrm{SO}_{2}$ flux rate measurements and 12 days of seismic recordings from early 2012 . We analyzed the statistical distributions of interevent times between transient seismic waveforms commonly associated with explosions and between peaks in the degassing time series. Both event types showed a periodic recurrence with a mode of $20-25 \mathrm{~s}$ and around $1 \mathrm{~h}$ for transients and degassing, respectively. The normalized interevent times were fitted by almost identical log-normal distributions. Given the actually very different time scales, this similarity potentially indicates a scale-invariant phenomenon. We could reproduce these empirical findings by modelling the occurrence of transients as a renewal process from which the degassing events were derived recursively with increasing probability since the previous degassing event. In this model, the seismic transients could be either produced by degassing processes within the conduit or by gas release at the lava lake surface while the longer intervals of the degassing events may be explained by accumulation of gas either in the magma column or in the juvenile gas plume. Additionally, we analyzed volcano-tectonic events, which behaved very differently from the transients. They showed the clustered occurrence of tectonic earthquakes.
\end{abstract}

\title{
1 Introduction
}

Villarrica Volcano is a highly active volcano in South America, which is known for its persistent seismic tremor and continuous degassing activity. Commonly, any seismic activity at a volcano is more or less directly attributed to the fluid dynamics within the plumbing system. Explosions are the violent releases of gas bubbles, while volcanic tremor and long-period (LP) events are frequently explained by moving gas, water or magma, that produce sustained reverberations along the walls of the conduits or pipes (Chouet, 1996). Even shear fractures (volcano-tectonic events) may be linked to changes in the pressure regime within the system which causes the opening (or closing) of new pathways for the fluids (Traversa \& Grasso, 2010). Intuitively, one would thus expect a direct correlation between degassing and intensity of seismic activity.

The degassing activity of a volcano is, for example, efficiently monitored by measuring the $\mathrm{SO}_{2}$ emission rate. Degassing magma releases $\mathrm{SO}_{2}$ in considerable amounts, making it a good proxy for the amount of outgassed mass. The intensity of the seismicity is commonly indicated by a measure of the mean seismic amplitude such as the Realtime Seismic Amplitude Measurements (RSAM) which is the root-mean square of the seismic amplitude over a given time interval, typically 10 min or $24 \mathrm{~h}$ (Endo \& Murray, 1991). Although positive correlations between RSAM and gas flux have been found at many volcanoes, there are some exceptions. An extensive overview was given by Salerno et al. (2018). These authors also proposed an explanation for this mismatch. They showed a generally good correlation between the weekly mean $\mathrm{SO}_{2}$ flux and daily mean RSAM at Mt. Etna for two years of continuous data. The daily variations however correlated to a much lesser degree. For Villarrica, Palma et al. (2008) also established a largely good correlation between $\mathrm{SO}_{2}$ emission rate and RSAM using data from 2000-2006. However, their data set was sparse. Mean flux rates for the correlation were obtained from a handful of daily measurements within 13 months; daily measurements consisted of 11 scans per day at most.

In this study we show continuous measurements of degassing rates recorded during daylight over three months at a rate of about one scan every 10 min using 3 scanning Mini-DOAS stations. Degassing and lava lake activity of Villarrica Volcano was ex- 
ceptionally high throughout the entire study period (Global Volcanism Program, 2014). During 10 days within this period, we also recorded the seismic activity close to the active vent. At first, we compared the two data sets visually for correlations. However, no correlation could be found whereupon we chose a statistical way to examine the relationship.Instead of comparing the time series directly, we analyzed the interevent times between transient seismic events - commonly classified as explosions (Calder et al., 2004; Ortiz et al., 2003; Palma et al., 2008) or long-period events (Richardson \& Waite, 2013) - and peaks in the degassing rate. This approach additionally mitigates the problem of the different lengths between the observation periods.

After the introduction of Villarrica, an overview of interevent times and the underlying concept of renewal processes in the context of seismology and volcanology is given. In section 4, the data sets are introduced in detail. For the analysis of interevent times, we distinguish three kinds of events: degassing events and two types of seismic events, namely the transients and volcano-tectonic earthquakes. A vital part of this paper (section 5.2) deals with the detection of different events and the compilation and completeness of the catalogs. Subsequently, we model and compare the their distributions of interevent times. In section 5.4, we propose a renewal process model to link the seismicity and degassing fluctuation and to explain the striking similarity of their interevent times. These distributions are contrasted with those of other volcanoes and of volcano-tectonic earthquakes from Villarrica.

\section{Villarrica volcano}

Villarrica is a $2847 \mathrm{~m}$ high, glacier-covered stratovolcano of basaltic to basaltic-andesitic composition, located in the Chilean Andes. It is one of the most active and dangerous volcanoes in South America. The volcanic activity consists of persistent degassing and occasional periods of mild explosive activity including ash and lava emissions (Global Volcanism Program, 2013).

The central vent hosts an active lava lake. Its depth varies more or less periodically by about $100 \mathrm{~m}$ within a few days (Richardson et al., 2014). Degassing activity at the lake surface was described in detail by Palma et al. (2008) and includes seething, bubble bursting and occasionally Strombolian explosions and lava fountains. Analysis of MODIS satellite data showed an elevated level of radiated heat throughout 2010-2012 (Global Volcanism Program, 2014), which was particularly enhanced during the period considered in this work.

The seismic activity is mainly characterized by a persistent tremor and extended periods of days to weeks during which short, transient bursts occur in approximately 1min intervals (Ortiz et al., 2003; Calder et al., 2004; Palma et al., 2008). The latter are commonly ascribed to explosive activity. Interestingly, while Palma et al. (2008) observed a good coincidence of seismic and visual explosive activity, Goto and Johnson (2011) reported a lack thereof. Thousands of repetitive events - denoted as LP events - were detected by Richardson and Waite (2013) during 2010-2012 and later described as Strombolian events (Richardson et al., 2014). We acknowledge that the terms "long-period event" and especially "explosion" are used in the literature addressing Villarrica to describe the transient waveforms. However, we think that usage of the term "explosion" insinuates a knowledge about the nature of theses events which in our view is not truly confirmed at present. The descriptive term "long-period" on the other hand is inappropriate for these waveforms if recorded close to the source since it commonly implies an upper frequency limit around $5 \mathrm{~Hz}$ (Chouet, 1996). Therefore, and to be consistent with a previous publication by Lehr et al. (2019), we prefer the neutral term "transient".

Volcano-tectonic events (VTs) are rather rare with 1-3 events per month reported by Calder et al. (2004) for the years prior to 2004, and respectively to about 100 events 
per week in early March 2012 (Mora-Stock (2015), this study). This difference however is probably the result of a different station set up rather than a true increase in the number of VTs.

Studies by Witter et al. (2004); Mather et al. (2004); Palma et al. (2008); Gurioli et al. (2008); Palma et al. (2011); Moussallam et al. (2016); Aiuppa et al. (2017) on gas flux rates, gas and magma composition indicate that vigorous convection of a twophase system (gas bubbles in liquid magma) takes place in the conduit. Convective twophase flow could also explain the notorious seismic and infrasonic unrest (Ripepe \& Marchetti, 2002). Between 2000 and 2011 the daily means of typical degassing rates of $\mathrm{SO}_{2}$ at Villarrica ranged between 0.5 and $20 \mathrm{~kg} / \mathrm{s}$ with an average at $5 \mathrm{~kg} / \mathrm{s}$ and rarely exceeded $50 \mathrm{~kg} / \mathrm{s}$ during periods of enhanced activity (Witter et al., 2004; Mather et al., 2004; Palma et al., 2008; Bredemeyer \& Hansteen, 2014).

Two studies by Moussallam et al. (2016) and Liu et al. (2019) investigated periodicities in gas parameters at sampling rates of $0.125-1.0 \mathrm{~Hz}$. Although both studies measured the $\mathrm{SO}_{2}$ flux at comparable locations of the plume (slightly above the crater rim and approximately $200 \mathrm{~m}$ above the magma surface (Moussallam et al., 2016)) Moussallam et al. (2016) showed periodicities at 30-380 s while Liu et al. (2019) found cycles of 345$714 \mathrm{~s}$. However, Moussallam et al. (2016) themselves were reluctant about their findings, since contemporaneously measured gas concentration and temperature lacked any periodicity. Interestingly, Liu et al. (2019) observed cycles on a similar scale (30-50 s) but in $\mathrm{SO}_{2}$ concentration within the plume (using a drone). These differences are possibly caused by an exceptionally low $\mathrm{SO}_{2}$ flux during Moussallam's campaign. From the largely lacking periodicities Moussallam et al. (2016) deduced an efficient mixing of raising gasrich and sinking degassed magma in the conduit resulting in a steady gas composition and flux rate. Liu et al. (2019) in contrast reported notable, audible bursts before the peaks in the $\mathrm{SO}_{2}$ concentration. Moreover, they found a significant lack of correlation between the $\mathrm{SO}_{2}$ concentration measured inside the plume directly above the crater and that measured by an instrument positioned approximately $100 \mathrm{~m}$ downwind at the crater rim. From the former finding, they concluded that the structure of the gas plume was predominantly formed by the (active) degassing process of the magma whereas from the latter, they inferred a nevertheless considerable influence of atmospheric effects (variable wind speed, turbulences, etc.). Due to a low $\mathrm{CO}_{2} / \mathrm{SO}_{2}$ molar ratio of around 1:1, they also suggested that gas bubbles remain coupled to the magma until reaching shallow depths and being actively released. Periodicities on time scales of hours to weeks were reported in $\mathrm{SO}_{2}$ degassing rates (Bredemeyer \& Hansteen, 2014) as well as seismic amplitude (Palma et al., 2008; Richardson et al., 2014)

\section{Renewal processes and interevent times in seismology and volcanol- ogy}

\begin{tabular}{|c|c|c|c|c|c|}
\hline $\begin{array}{l}\text { Period of Observa- } \\
\text { tion }\end{array}$ & Activity & $\mathrm{Cv}$ & Distribution & Reference & Remarks \\
\hline Stromboli & & & & & \\
\hline Sept. 1997 & $\mathrm{SE}$ & $\approx 1$ & & $\begin{array}{l}\text { Bottiglieri et } \\
\text { al. }(2005)\end{array}$ & \\
\hline $\begin{array}{l}\text { May } 2002 \text { - Jan. } \\
\text { 2003, Oct. } 2006 \text { - } \\
\text { Mar. 2007, Sept. } \\
2010 \text { - May } 2011\end{array}$ & SE, Effusion & $\approx 0.8$ & Exponential & $\begin{array}{l}\text { Martino et al. } \\
(2012)\end{array}$ & \\
\hline
\end{tabular}




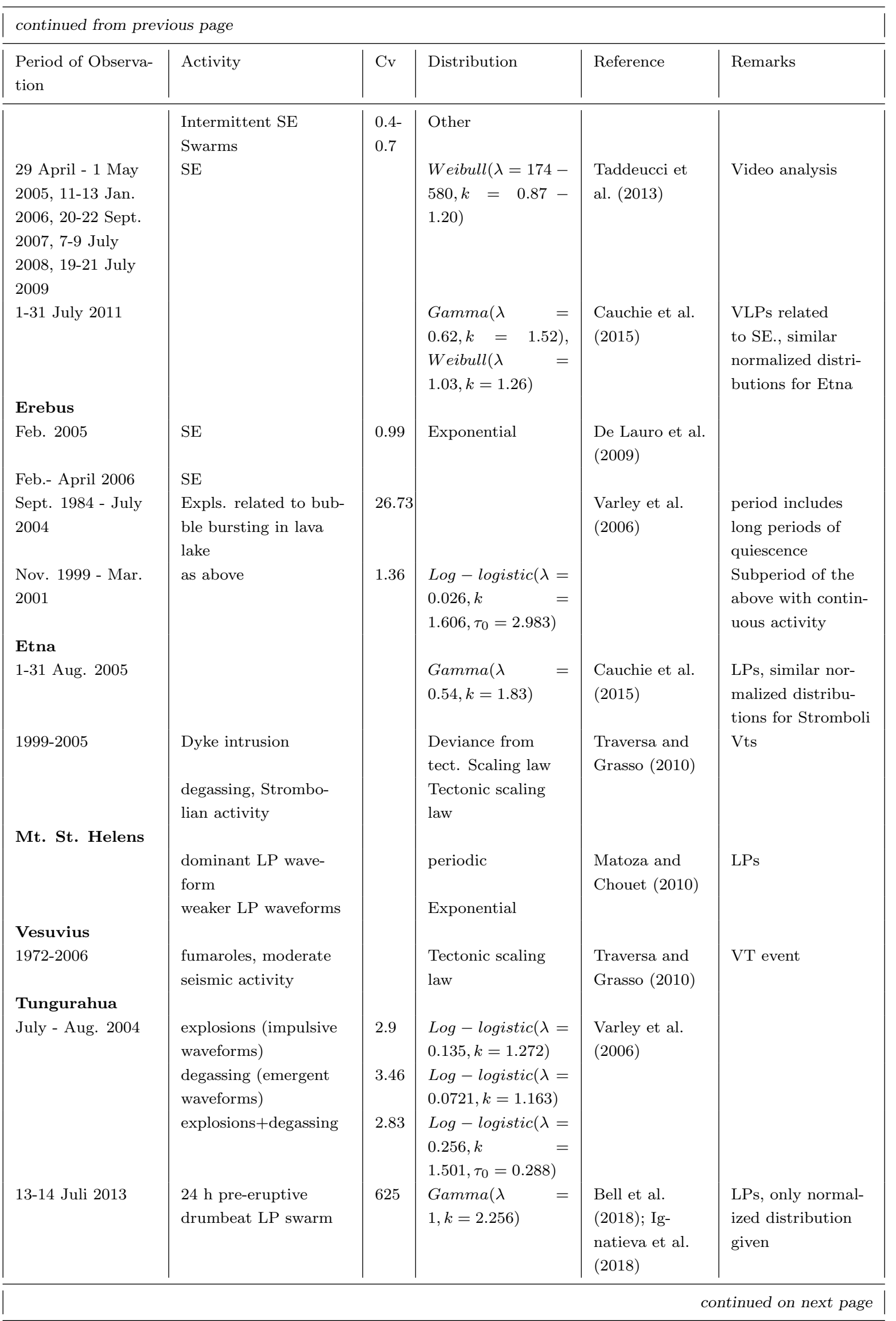

29 April - 1 May 2008, 19-21 July 2009 1-31 July 2011 159

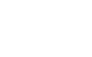

\section{Erebus}

Feb.- April 2006

Sept. 1984 - July

Nov. 1999 - Mar. lak

pls. related to bubas above

degassing, Strombodominant LP wave-

fumaroles, moderate explosions (impulsive waveforms) explosions+degassing

$24 \mathrm{~h}$ pre-eruptive drumbeat LP swarm 


\begin{tabular}{|c|c|c|c|c|c|}
\hline $\begin{array}{l}\text { Period of Observa- } \\
\text { tion }\end{array}$ & Activity & $\mathrm{Cv}$ & Distribution & Reference & Remarks \\
\hline \multicolumn{6}{|l|}{$\begin{array}{l}\text { Volcan de Col- } \\
\text { ima }\end{array}$} \\
\hline $\begin{array}{l}\text { May } 2002 \text { - Sept. } \\
2004\end{array}$ & $\begin{array}{l}\text { degassing (emergent } \\
\text { waveforms), explosions } \\
\text { (impulsive waveforms) }\end{array}$ & $\begin{array}{l}1.05- \\
1.48\end{array}$ & $\begin{array}{l}\text { Log-logistic, } \\
\text { Gamma, Weibull } \\
\text { depending on } \\
\text { event type and } \\
\text { subperiod }\end{array}$ & $\begin{array}{l}\text { Varley et al. } \\
(2006)\end{array}$ & $\begin{array}{l}5 \text { subperiods were } \\
\text { analyzed }\end{array}$ \\
\hline \multicolumn{6}{|l|}{ Karymsky } \\
\hline 1997 & $\mathrm{SE}$ & 0.68 & $\begin{array}{l}\text { Weibull }(\lambda= \\
0.157, k= \\
\left.1.234, \tau_{0}=1.009\right)\end{array}$ & $\begin{array}{l}\text { Varley et al. } \\
(2006)\end{array}$ & $\begin{array}{l}2 \text { representative } \\
\text { days }\end{array}$ \\
\hline 1998 & $\mathrm{SE}$ & 0.53 & $\begin{array}{l}\text { Weibull }(\lambda= \\
0.33, k= \\
\left.1.393, \tau_{0}=1.0085\right)\end{array}$ & & $\begin{array}{l}3 \text { representative } \\
\text { days }\end{array}$ \\
\hline
\end{tabular}

Table 1. Overview of studies addressing interevent times of volcanic seismicity. Parameters of probability density distributions were adapted to meet the definitions given in Table 2 if necessary. $\mathrm{SE}=$ Stromboilan explosion.

The occurrence of events in time is mathematically equivalent to points distributed on the positive real line, provided that their duration is negligible. Sequences of such events can be modeled stochastically by their interevent times, that is, the duration between two consecutive events. If these are independent and identically distributed the sequence is a renewal process. Renewal theory originated from queuing problems and failure time analysis in engineering and is part of the broader concept of point processes (Daley \& Vere-Jones, 2003). The best-known and most fundamental renewal process is the Poisson process which has exponentially distributed interevent times. Poisson processes characterize completely random occurrence of events. For example, the global occurrence of large earthquakes or volcanic eruptions (la Cruz-Reyna, 1991) follows a Poisson process. In contrast, processes can be more clustered in time, e.g. as mainshock-aftershock sequences, or more periodically, in which case other distributions are used. For example, Bell et al. (2018) used a Gamma distribution to describe the quasi-periodic occurrence of repetitive long-period events before an eruption of Tungurahua.

In statistical seismology, the analysis of interevent times has gained new interest after the proposition of a universal scaling law by Bak et al. (2002) and Corral (2003). This scaling function is a Gamma distribution (Corral, 2003; Traversa \& Grasso, 2010):

$$
f(t)=C t^{\gamma-1} \exp \left(\frac{-t}{a}\right)
$$

with $\gamma=0.67 \pm 0.05, a=1.58 \pm 0.15$ and $C=0.5 \pm 0.1$. When scaled by the corresponding rate, interevent time distributions of tectonic earthquake sequences from different regions collapse to Eq. 1. The theoretical foundation and the usefulness of Eq. 1 have been widely disputed, e.g. by Molchan (2005); Saichev and Sornette (2006); Touati et al. (2009). Nevertheless, on an empirical base, the scaling property and the fit to Eq. 1 have been demonstrated successfully for event catalogs across a wide range of scales such as acoustic emissions from fracturing rocks (Davidsen et al., 2007), induced seismicity at mining and drilling sites (Davidsen \& Kwiatek, 2013), VT events (Bottiglieri et al., 2009; Traversa \& Grasso, 2010) and regional tectonic events (Corral, 2003). Therefore, 
we use it here as a reference to test whether a group of events behaves like shear fractures.

Renewal processes were also used to model volcanic eruption sequences on different scales. Repose intervals of indexed historic eruptions at numerous volcanoes have been fitted by exponential, Gamma, Weibull and other distributions (see Marzocchi and Bebbington (2012) for references). Notably, Dzierma and Wehrmann (2010) analyzed the record of Villarrica Volcano and found the best fit for an exponential distribution (compared to Weibull and Log-logistic). In analogy to earthquake statistics, Sanchez and Shcherbakov (2012) derived a scaling function for major volcanic eruptions of 26 volcanoes, which is a log-normal distribution. On a smaller scale, explosions, volcano-tectonic earthquakes, long-period and very-long-period events - usually identified from geophysical monitoring data - were analyzed for a number of volcanoes. A non-exhaustive overview stating the type of events and, if provided, the distribution of interevent times, is given in Table 1. In this list, the systems of Stromboli and Erebus are usually considered the most similar to Villarrica as they are all basaltic open-vent systems. The majority of these studies is based on seismological records. The analysis of interevent times using gas-related measurements is rather uncommon. One exception was provided by Pering et al. (2015) who used an $\mathrm{SO}_{2}$ camera to detect gas bursts at Mt. Etna. They found a unimodal, skewed left distribution with a median of about $5 \mathrm{~s}$ and a mode around $4 \mathrm{~s}$.

\section{Data}

\subsection{Seismic data}

The seismic data were acquired during the installation of a dense local network comprising 75 seismometers during 1-12 March 2012 (Rabbel \& Thorwart, 2019). Three stations were deployed at the crater rim (KRA1-KRA3) and the remaining instruments were distributed on and around the volcanic edifice (Fig. 1). One of the crater stations (KRA2) ceased to operate after 5 days whereas the other two (KRA1, KRA3) recorded for 12 days. Due to their proximity to the active vent, they provided the most detailed recording of its seismic activity. The stations were equipped with 3-component and 1-component SM6/U 4.5-Hz geophones, respectively, and DSS-cubes sampling at $100 \mathrm{~Hz}$. We verified in a laboratory experiment, that their data can reliably be recovered up to a tenth of the nominal frequency (i.e. $0.45 \mathrm{~Hz}$ ) by correcting for the instrument response.

The raw data were merged to 25 -h-long sections and a constant trend removed. These sections contained $24 \mathrm{~h}$ of data and additional $30 \mathrm{~min}$ at the beginning and end, which overlapped with the previous and next sections. The data was filtered below $25 \mathrm{~Hz}$ and resampled at $50 \mathrm{~Hz}$. Subsequently, the instrument response was removed. Before the final analysis, the overlap was sliced off to eliminate potential edge effects from filtering.

The seismic signal throughout the network was dominated by a persistent unrest with overlain transient increases in amplitude which originated from the crater region (Lehr et al., 2019). At the crater rim, these transients last from a few seconds to several tens of seconds and contain frequencies up to $16 \mathrm{~Hz}$. Fig. 2 shows a 6h-long record section (top) and spectrograms and waveforms (middle) of the transient events as seen by a near-source seismic station (KRA1) at the crater rim. The bottom panel includes a similar transient signal at the distant station VS12. Note the substantial alteration of the waveform with distance. We denote generally all the short-lived, more or less impulsive amplitude increases recorded at KRA1-3 as transients and refrain from any further classification or attribution of source mechanisms.

Throughout the campaign, several hundreds of volcano-tectonic events (Fig. 2, bottom) occurred about $5 \mathrm{~km}$ to the east of the summit (Mora-Stock, 2015) at depths between $1-5 \mathrm{~km}$. Their frequency content is above $5 \mathrm{~Hz}$; they have clear first arrivals, $\mathrm{P}-$ and S-phases and last only for a few seconds. Their signal is easily detected at stations 


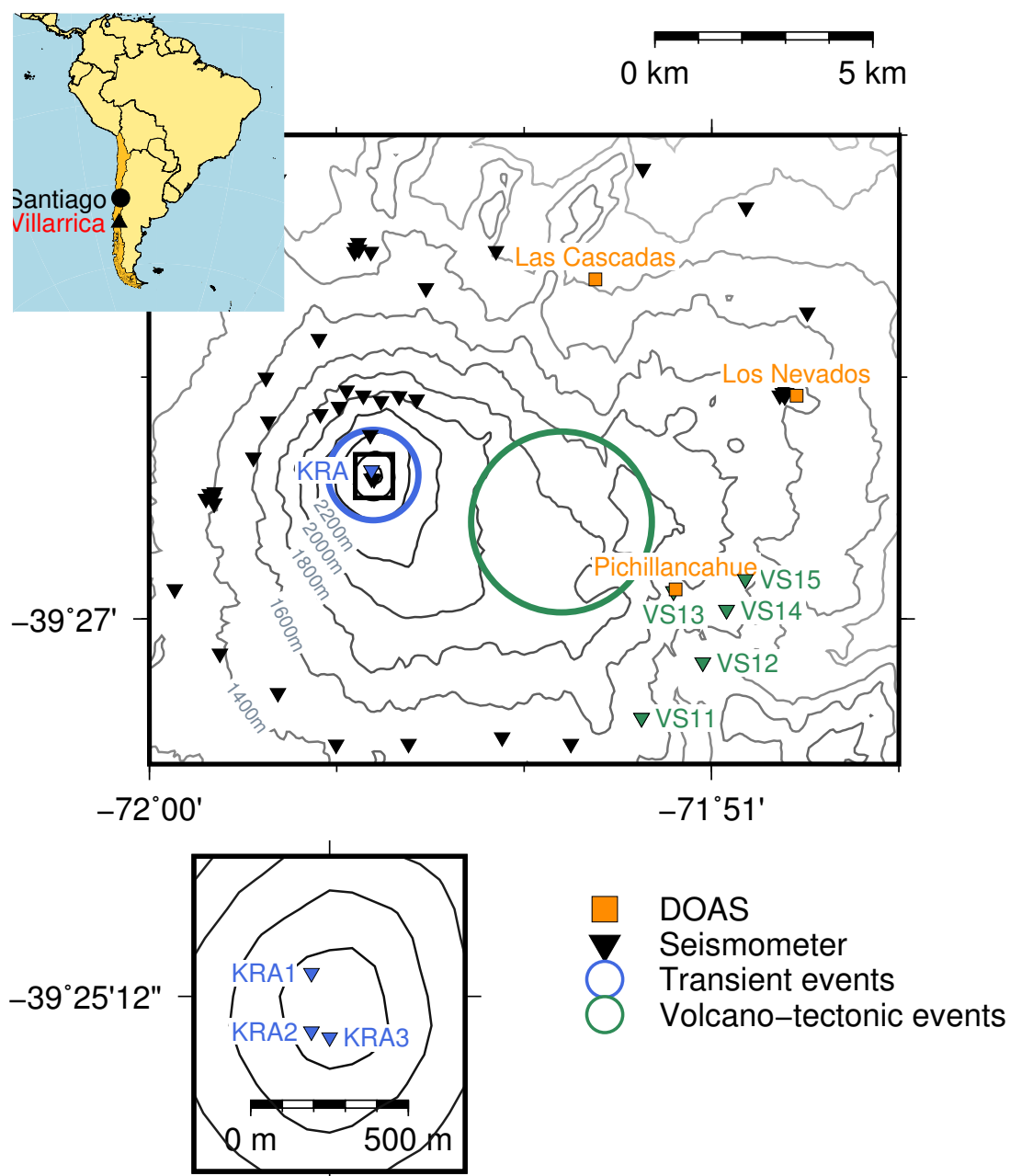

$-71^{\circ} 56^{\prime} 24^{\prime \prime}$

Figure 1. Locations of the three scanning Mini-DOAS stations (orange squares), 46 of the 75 deployed seismometers (black triangles), origins of transient and VT events (blue and green circles, respectively). Downwind distances of DOAS instruments from conduit center are (from N to S): Las Cascadas $6.76 \mathrm{~km}$, Los Nevados $9.84 \mathrm{~km}$, Pichillancahue $7.39 \mathrm{~km}$. Seismometers used for the detection of transient and VT-events are colored in blue and green, respectively. 
along the perimeter of the volcano but is masked by the volcanic noise at stations within $2-5 \mathrm{~km}$ to the crater and especially at the crater stations KRA1-3.

\section{2 $\mathrm{SO}_{2}$ flux}

Differential optical absorption spectroscopy (DOAS) is a common technology to measure e.g. the $\mathrm{SO}_{2}$ content of a volcanic gas plume (Jochen Stutz, 2008; Platt et al., 2018). In 2009 and 2010, three permanent scanning Mini-DOAS stations were deployed around Villarrica Volcano at distances of about $7-10 \mathrm{~km}$ from the active crater in order to continuously monitor its $\mathrm{SO}_{2}$ emission rates (Fig. 1). For the present study we used the data that was acquired during a 3-months period from 1 January to 31 March 2012 which generously covers the period of the seismic deployment. The NOVAC-type DOAS instruments scan across the sky several kilometers downwind of the volcano and measure spectra of the incoming scattered sunlight in order to acquire $\mathrm{SO}_{2}$ density profiles of the volcanic gas plume vertically to its transport direction (Galle et al., 2010). By this means the instruments intercept largely homogenized gas plumes, which are in thermal equilibrium with the surrounding atmosphere. At wind speeds around $10 \mathrm{~m} / \mathrm{s}$ the typical age of the plume is 10-15 min since emission from the vent. $\mathrm{SO}_{2}$ slant column densities at each scan angle were retrieved from the 310-320 nm wavelength range of the recorded sunlight spectra by means of DOAS (Jochen Stutz, 2008). Additionally to the measured sunlight spectra an $\mathrm{SO}_{2}$ absorption spectrum from Vandaele et al. (1994), an $\mathrm{O}_{3}$ absorption spectrum (Voigt et al., 2001), and a Ring spectrum to mitigate the Ring effect (Grainger \& Ring, 1962) were included in the DOAS fit. Plume transport velocities required to calculate the flux from the $\mathrm{SO}_{2}$ density profiles were estimated using archived wind speed data of the National Oceanic and Atmospheric Administrations (NOAA) Global Forecast System. Plume transport directions were determined by single station triangulation using the $\mathrm{SO}_{2}$ density profiles in combination with the best available information on plume height. The latter either was determined by triangulation between the simultaneously acquired $\mathrm{SO}_{2}$ density profiles of two DOAS instruments (Johansson et al., 2009), or, if such simultaneous measurements were not available, the plume was assumed to be stationary at the level of the emission source. The method requires UV-light, thus it only works during daylight, and each scan through the gas plume takes 5-15 min depending on the light conditions. This results in an irregularly spaced time series with gaps during nighttime. The degassing rates of $\mathrm{SO}_{2}$ varied between 0.14 and $80.91 \mathrm{~kg} / \mathrm{s}$ at a mean rate of $5.96 \mathrm{~kg} / \mathrm{s}$, a standard deviation of $5.7 \mathrm{~kg} / \mathrm{s}$ and a median of $4.28 \mathrm{~kg} / \mathrm{s}$ during the study period.

\section{Methods}

At first, we directly compared the seismic amplitude with the degassing rate. Due to the lack of visible correlation, we proceeded with the analysis of different seismic and degassing events. The steps are explained in the subsequent subsections starting with a recapitulation of the trigger algorithm and the definition of the different event types. Based on the principle of the seismic trigger, we derived the idea of gas events. Thereafter, the statistical methods are introduced to analyze the interevent times. Finally, using the resulting distributions of interevent times as input, a numerical model of a renewal process is proposed to couple the degassing and seismic activity.

\subsection{Comparison of seismic amplitude and $\mathrm{SO}_{2}$ flux}

Frequency analysis indicated a concentration of the seismic energy at the crater rim in two frequency ranges: $0.5-5 \mathrm{~Hz}$ and $7.5-10 \mathrm{~Hz}$ (Supporting figure S1). For these frequency bands, as well as $0.5-24.9 \mathrm{~Hz}$, the median of the absolute amplitude was computed using windows of $40.96 \mathrm{~s}$ (2048 data points), overlapping by $50 \%$. Similar to the wellknown RSAM, the result can be used as an indicator of the intensity of the seismic ac- 

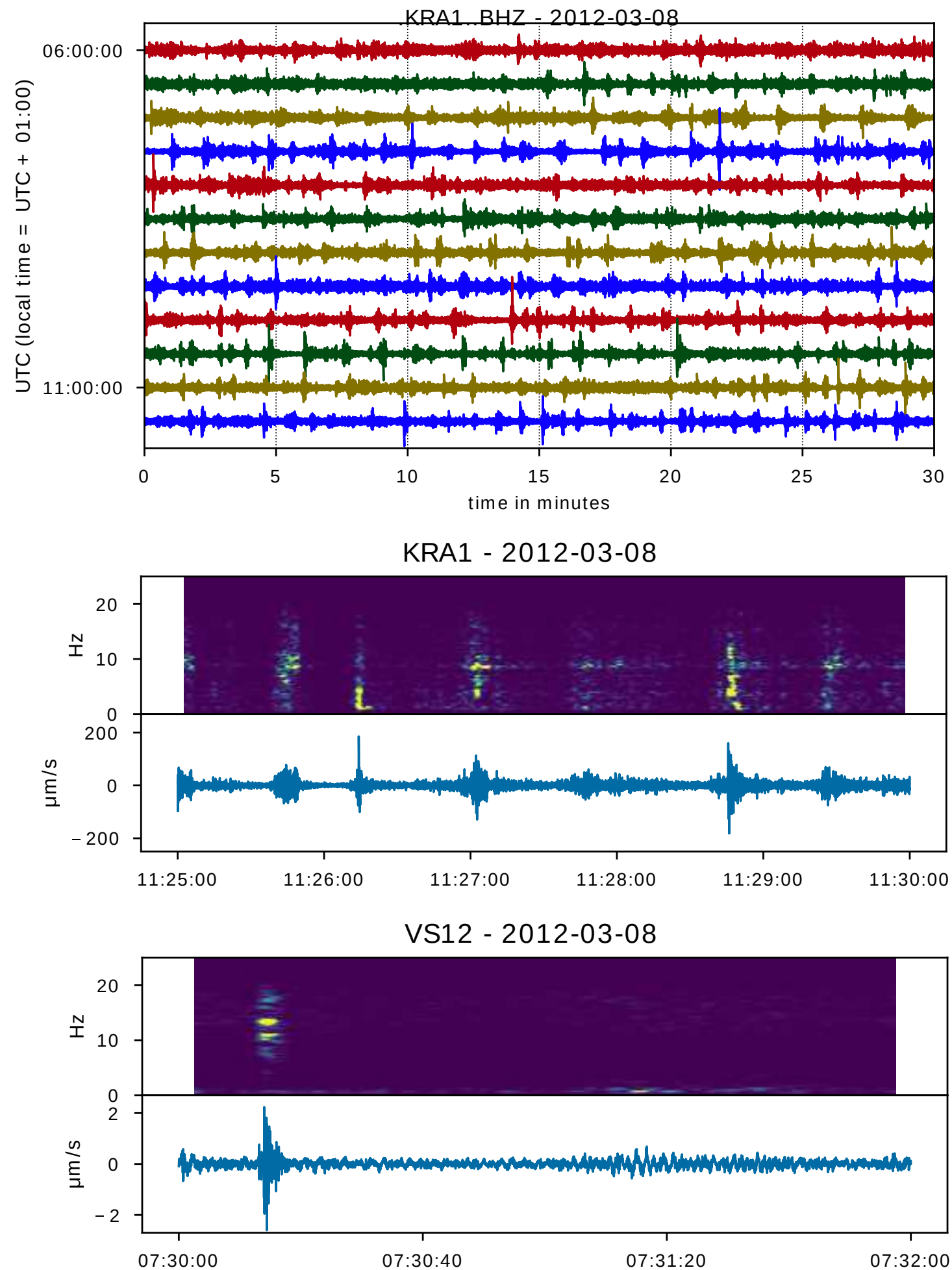

Figure 2. top: Seismicity recorded at the crater rim, $\mathrm{f}=0.5-16 \mathrm{~Hz}$. We refer to the abundant, short-lived temporary increases in amplitude and spikes as "transient events"; middle: Spectrogram and detailed seismogram of transients at crater; bottom: Spectrogram and seismic trace of volcano-tectonic event (c. 07:30:10) and transient event (c. 07:31:10) $5 \mathrm{~km}$ SE of the crater. 
tivity. The main difference is, that RSAM is based on the mean whereas here, we used the median because it is less sensitive to outliers. For comparison with the $\mathrm{SO}_{2}$ flux the obtained amplitudes were smoothed again using a running median in windows of $1 \mathrm{~h}$ and $24 \mathrm{~h}$, respectively. The $\mathrm{SO}_{2}$ flux data were averaged using the median of measured data points in consecutive $24 \mathrm{~h}$ - and $1 \mathrm{~h}$-long time windows. Note however, that the $24 \mathrm{~h}$-interval only includes data from during day light. The minimum and maximum in the respective time windows indicate the variability of the flux.

\subsection{Event detection}

A simple and widely used method for the detection of seismic events is the ratio of short-term average to long-term average (STA/LTA). Two types of seismic events were investigated: the transient waveforms from the crater and the volcanic-tectonic earthquakes originating southeast of the crater. Then the concept of the trigger was extended to derive a definition of $\mathrm{SO}_{2}$ (or degassing) events.

For the STA/LTA trigger, the mean of the squared amplitude is computed in a short and a long time window. These are slid along the trace and a trigger function is obtained from the ratio of the two averages. A trigger is declared, when the trigger function exceeds a predefined threshold and terminated when the function falls below a second, usually lower, threshold. The window lengths and thresholds need to be adapted to the targeted events and depend on their duration, dominant frequency and the amount of background noise. We implemented the trigger algorithm such that the ratio is evaluated at the common center of the STA and LTA windows. In a second variation, we applied the median instead of the mean of the squared amplitude.

Eventually we were interested in the distribution of interevent times. We found, that these were quite sensitive to the choice of the trigger method and its corresponding parameters. Therefore, we applied additional techniques to refine the catalog, depending on the type of events. We refer to a final collection of events obtained by a given procedure as catalog.

\subsubsection{Transient events}

For the detection of the transient events from the crater, the stations KRA1 and KRA3 were used and both stations needed to be triggered to declare an event (network coincidence trigger). The data were filtered between 0.45 and $16 \mathrm{~Hz}$, owing to the broad variety of spectral content of these events. We tested combinations of STA windows of $6,8,12$ and $16 \mathrm{~s}$ and LTA windows of $16,24,32,48$ and $64 \mathrm{~s}$. Combinations at which both windows would be of the same length were omitted. The trigger thresholds were set to $1.25,1.5$ and 2 and the offset threshold was always fixed to $70 \%$ of the onset.

In order to evaluate the quality of the detection methods, we picked three 2-hour sequences manually. However the classification of a signal as event is to some degree subject to interpretation. The success was quantified by the amount of correctly $\left(n_{\text {pos }}\right)$ and falsely $\left(n_{\text {neg }}\right)$ detected events compared to the number of reference event $n_{\text {ref }}$ as

$$
s=\sqrt{\left(1-\frac{n_{\text {pos }}}{n_{\text {ref }}}\right)^{2}+\left(\frac{n_{n e g}}{n_{\text {ref }}}\right)^{2}}
$$

Hence, the amount of missed and falsely detected events was minimized in a least-square sense. A successful detection was declared if a reference had an overlapping counterpart in the automatically generated catalog. A falsely detected event arose if no corresponding reference event could be found. In doing so, we ignored the differences regarding onset times and duration between the automatically and manually detected events. Hence, we only tested whether the algorithm was capable of finding an event at all. 

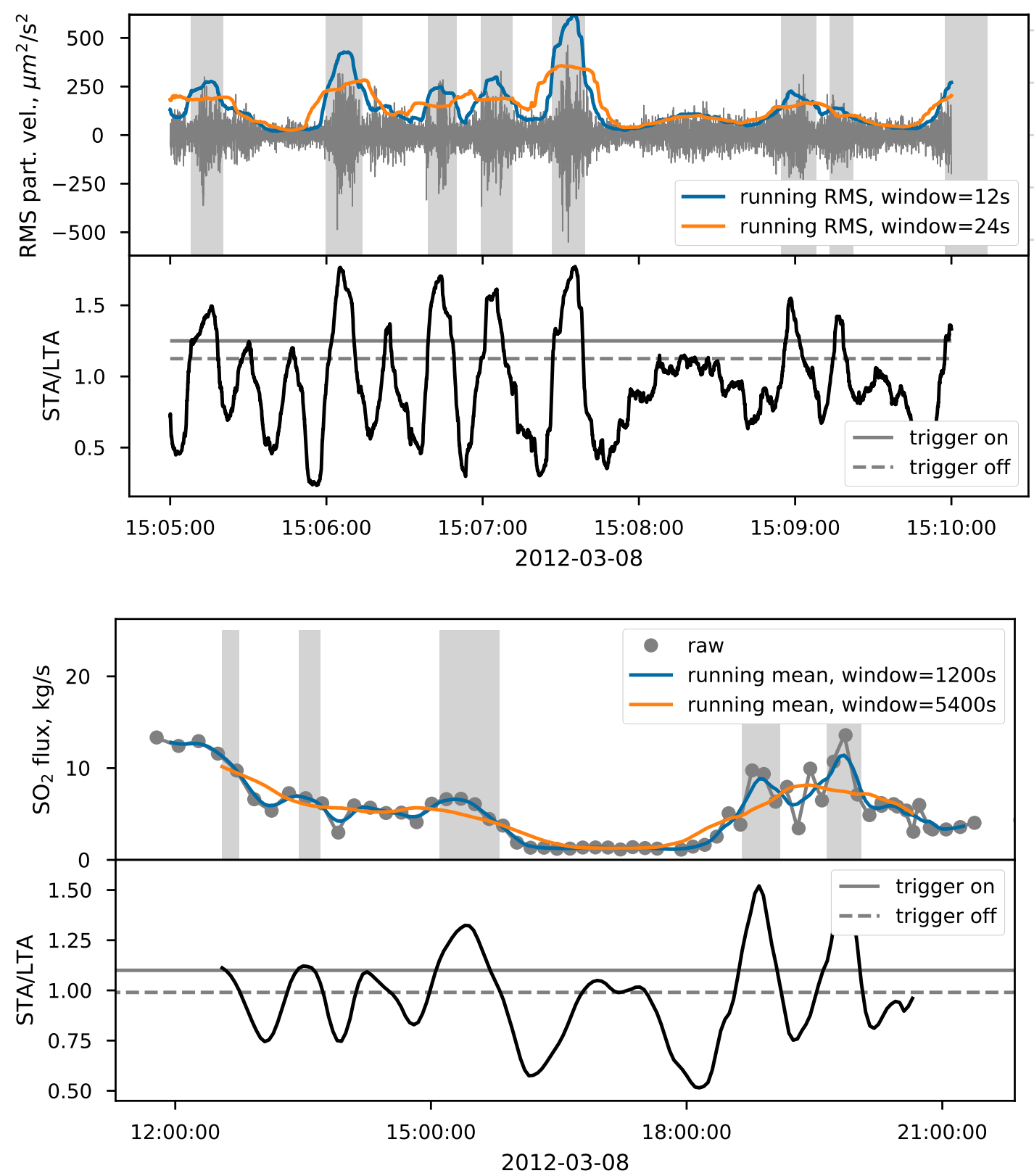

Figure 3. Event detection using an STA/LTA trigger on seismic (top) and gas (bottom) data: the trigger function (respective lower panels) results from the ratio between the average amplitude in a short (blue) and a long (red) window running in parallel. An event starts when the trigger function exceeds the "on"-threshold and terminates when the function drops below the "off"-threshold. For the seismic data the root-mean-square instead of the mean amplitude was used. 


\subsubsection{VT-events}

For the detection of VT-events, we initially applied an STA/LTA trigger using the stations VS11-15 and filtering the data between 5 and $10 \mathrm{~Hz}$. The catalogs were also quite influenced by the window lengths. However, due to the relatively low number of events it was feasible to revise the catalog manually. This included the removal of regional earthquakes and quakes from parts of the edifice other than the main source region of VTs. Furthermore, several weak VTs were added.

\subsection{3 $\mathrm{SO}_{2}$ events}

In analogy to seismic events, which are essentially local maxima in seismic amplitude, we determined $\mathrm{SO}_{2}$ events by applying the STA/LTA trigger to the gas time series. We experimented with window lengths of $10 \mathrm{~min}, 15 \mathrm{~min}, 20 \mathrm{~min}$ and $30 \mathrm{~min}$ for STA and $30 \mathrm{~min}$, $45 \mathrm{~min}, 60 \mathrm{~min}, 90 \mathrm{~min}$ and $120 \mathrm{~min}$ for LTA. Thresholds were set to 1.01 and 1.1. It should be noted that the original measurements were provided approximately every $10 \mathrm{~min}$. The data were linearly interpolated to regular spaced $180 \mathrm{~s}$-long intervals for gaps of less than $0.5 \mathrm{~h}$ and set to None otherwise. An example is shown in Fig. 3, bottom.

\subsection{Statistical aspects of interevent times}

We defined the interevent time as the time difference between two consecutive arrivals of events and analyzed their frequency distributions by computing histograms. In order to describe the overall shape of the distributions, we used the coefficient of variation $C_{v}$ which is defined as the mean divided by the standard variation of the interevent times. This term has been widely used in statistical seismology to differentiate between random processes $\left(C_{v}=1\right.$, exponential distribution of interevent times), periodic processes $\left(C_{v}<1\right)$ and processes clustered in time $\left(C_{v}>1\right.$, power-law distribution).

Since the three kinds of events occur on different time scales, we normalized the distributions by the respective means to compare their geometries. This procedure was inspired by the much debated, postulated scale invariance of the interevent times of tectonic earthquakes (see e.g. de Arcangelis et al. (2016) for a review).

Selected catalogs of each rescaled data set were modeled as common probability density distributions using the build-in maximum-likelihood estimation of scipy.stats. We tested for log-normal, exponential, log-logistic, Gamma and Weibull distributions (Table 2) and selected by the Akaike Information Criterium (AIC, Akaike (1974)).

\subsection{Renewal process model of coupled seismicity and degassing}

Furthermore, we developed a statistical model in which the occurrence of degassing events was derived from the occurrence of transients. The transients were modeled as a renewal process with interevent times drawn from a probability density distribution. We then assumed that the probability of a degassing event increases with the number of seismic events since the last degassing:

$$
p\left(E_{S_{2}} \mid n_{T R A}\right)=f\left(n_{T R A}\right)
$$

A second series of degassing events was derived by testing for each transient whether it triggered a gas event. In other words, we performed a Bernoulli trial on each transient with the probability of success (=triggering) given by Eq. 3 and the current number of transients since the last degassing. A Bernoulli trial is a random experiment with only two outcomes, 0 or 1 , that have probabilities $q$ and $p$, respectively, with $q+p=1$. The time of a gas event was defined as the time of the transient that triggered the degassing. This model was simulated numerically using Algorithm 1 for different $f\left(n_{T R A}\right)$. Each 


\begin{tabular}{cll}
\hline Name & Definition & \\
\hline Exponential & $f(t ; \lambda)=\frac{1}{\lambda} e^{(-x / \lambda)}$ & $t, \lambda>0$ \\
Gamma & $f(t ; \lambda, k)=\frac{1}{\Gamma(k)}\left(\frac{t}{\lambda}\right)^{k-1} e^{\frac{t}{\lambda}}$ & $t, \lambda, k>0, \Gamma(k)$-Gamma fct. \\
Weibull & $f(t ; \lambda, k)=\frac{k}{\lambda}\left(\frac{t}{\lambda}\right)^{k-1} e^{-(t / \lambda)^{k}}$ & $t, \lambda, k>0$ \\
Log-logistic & $f(t ; \lambda, k)=\frac{(k / \lambda)(t / \lambda)^{k-1}}{\left(1+(x / \lambda)^{k}\right)^{2}}$ & $t, \lambda, k>0$ \\
Log-normal & $f(t ; \lambda, k)=\frac{1}{k t / \lambda \sqrt{2 \pi}} \exp \left(-\frac{\ln ^{2}(t / \lambda)}{2 k^{2}}\right)$ & $t, \lambda, k>0$
\end{tabular}

Table 2. Parametrizations of the probability density functions used in this study. $k$ and $\lambda$ denote shape and scale parameters, respectively.

experiment was repeated 100 times using sequences of 20,000 transients. The interevent times of the transients were modeled according to the results from the observational data (a log-normal distribution). For $f$, we tested a step function (meaning $E_{\mathrm{SO}_{2}}$ happens after $m$ transients), a constant probability and a linear and polynominal increase. The parameters for $f$ were adapted by trial and error to match the observed data. From Eq. 3, another two interesting relations can be derived. The probability of an $E_{\mathrm{SO}_{2}}$ after the $k$-th transient since the last degassing is $P\left(E_{S O 2}\right.$ after $\left.\mathrm{k} E_{T R A}\right)=\sum_{k=1}^{N} p(k)$ (corresponding to a cumulative distribution function). The probability at the $k$-th transient is given as the derivative.

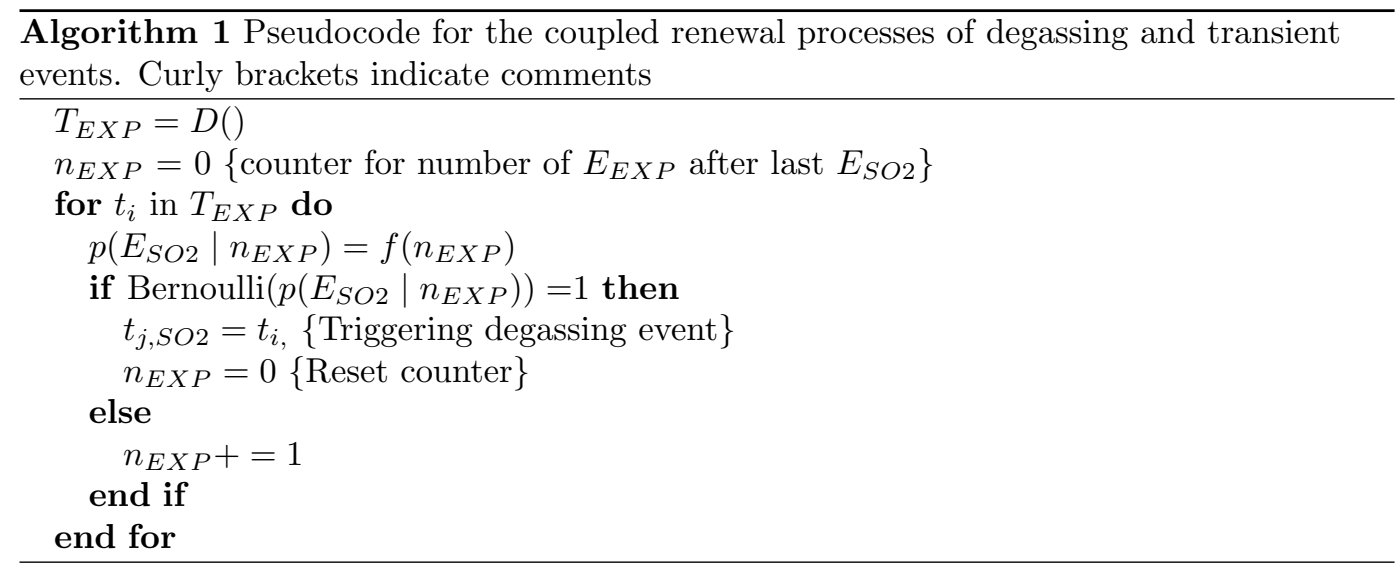

\section{Results}

\subsection{Comparison of seismicity and $\mathrm{SO}_{2}$ flux}

A comparison of the seismic and $\mathrm{SO}_{2}$ flux time series did not reveal any correlation (Fig. 4). On a long-term scale (top panel of Fig. 4), there was no accordance between the two data sets, even under the assumption of a time shift of several days. Such a shift might result from a delayed reaction of the seismicity to a change in the degassing regime or vice versa. On a more detailed scale (bottom panel of Fig.4), single days and frequency ranges exhibited a seemingly good consistency between gas flux and $7.5-10 \mathrm{~Hz}$ - seismic amplitude, e.g. days 62, 65, 70 (Fig. 4). However, when taking into account all available days, the overall correlation was poor. 

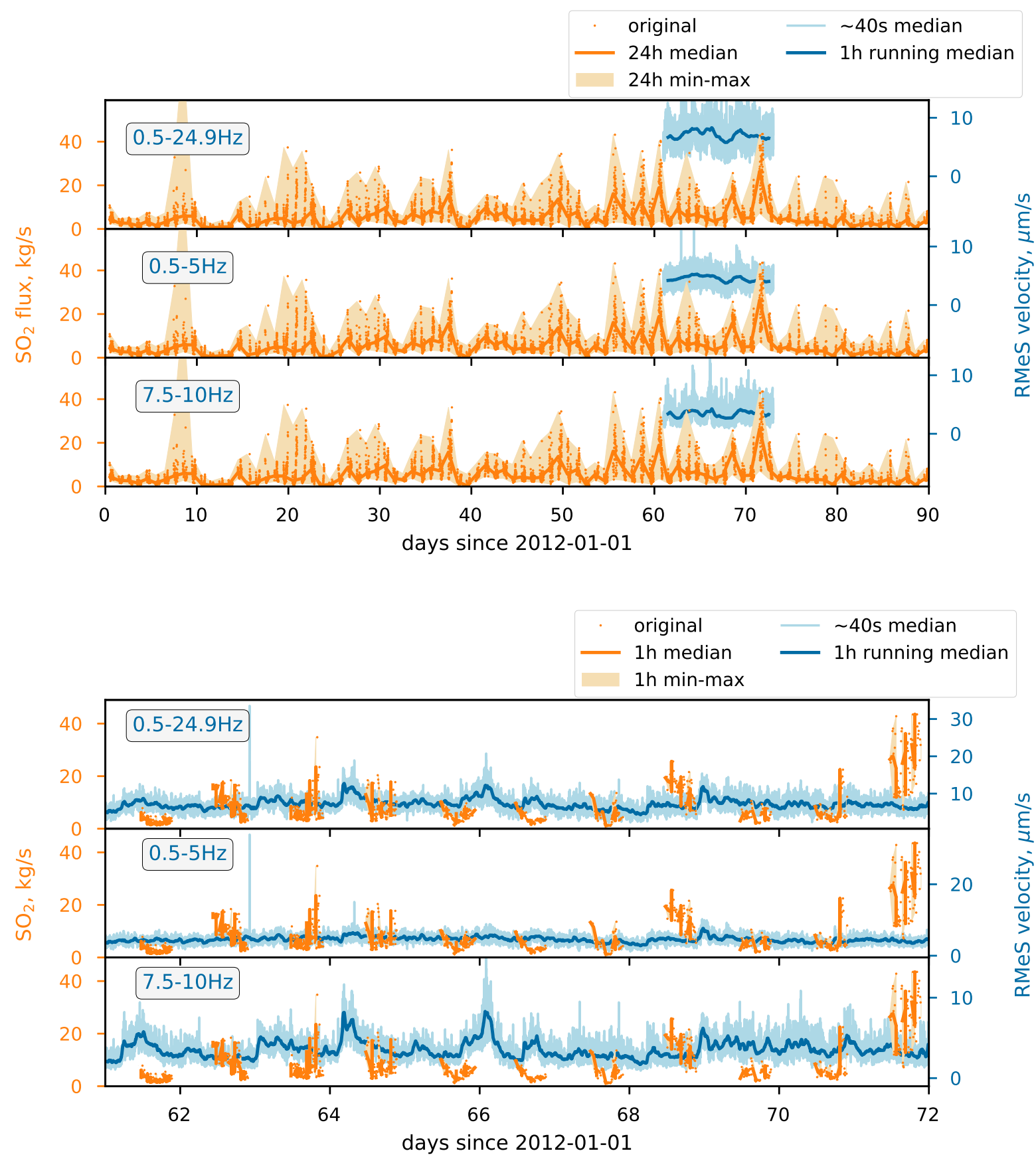

Figure 4. Comparison of $\mathrm{SO}_{2}$ flux (orange, left) and seismicity at station KRA1 (blue, right) at different frequencies. $\mathrm{SO}_{2}$ flux is given as median flux in consecutive $24 \mathrm{~h}$ (top) and $1 \mathrm{~h}$ (bottom) intervals and is identical in all panels. Seismicity is filtered as indicated and given as $24 \mathrm{~h}$ and $1 \mathrm{~h}$ running median of RMeS velocity in $20.48 \mathrm{~s}$ windows at $5.12 \mathrm{~s}$ intervals. There is only a poor correlation. 

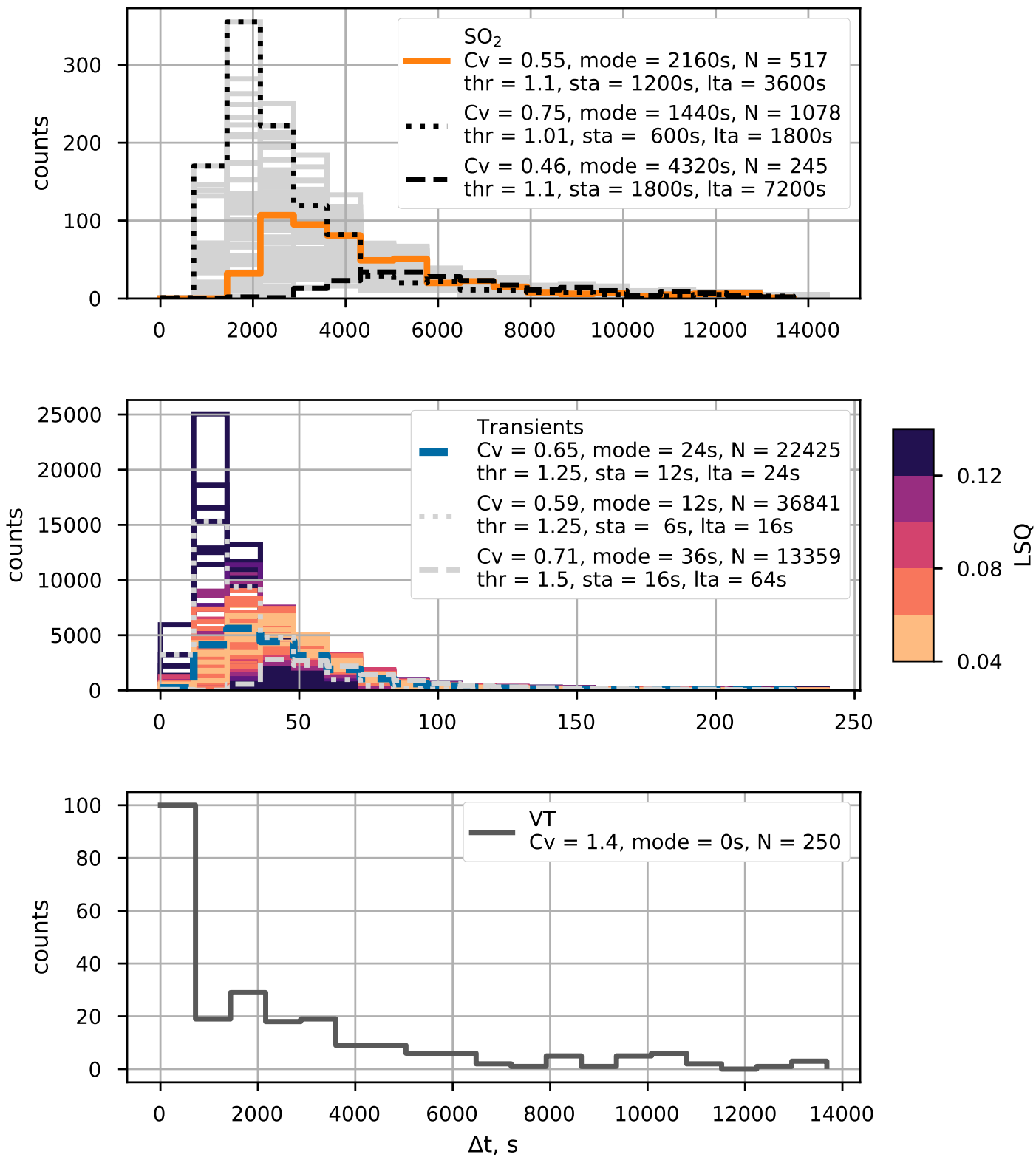

Figure 5. Distributions of interevent times for the three event types. $\mathrm{SO}_{2}$ (top): All catalogs are shown in gray and two extremes are highlighted in black. The final selection is marked in orange. Transients (middle): Tested catalogs are color-coded by their success rate (Eq. 2) compared to manual picking. Low values/light colors indicate a high success. Two extreme cases are marked by dotted and dashed lines, respectively. The final selection is highlighted in blue. VT (bottom): Only data from the manually revised catalog is shown. Trigger parameters of highlighted catalogs and coefficient of variation $(\mathrm{Cv})$, mode and total number of events $(\mathrm{N})$ of corresponding distributions are given in the panels. 


\subsection{Interevent times}

The empirical frequency distribution of the interevent times of all three event types ( $\mathrm{SO}_{2}$, transients, VTs) was analyzed by histograms (Fig. 5). The results for the degassing and transient events depended substantially on the trigger parameters. Generally, distributions resulting from extreme parameter combinations formed the margins of the ensemble. Only results for which the amplitudes in the STA and LTA windows were averaged by the mean are presented here. Separate plots of each catalog, including the results for median averaging are provided in the supporting information (Figs. S2-4).

For all catalogs of transient events, the histograms of interevent times indicated skewed right, unimodal distributions while the number of detections ranged roughly from 10,000 to 50,000. The coefficient of variation $C_{v}$ increased with threshold and varied between 0.4 and 2, thus giving no clear indication of the type of process. However, $C_{v}$ for catalogs, that yielded a quality of 0.06 or better, fell between 0.4 and 0.7 which consistently indicated a rather periodic process. The best correspondence between an automatically generated catalog and the manual picks was achieved for mean/threshold $=1.25 / \mathrm{STA}=12 \mathrm{~s} / \mathrm{LTA}=24 \mathrm{~s}$ with $\mathrm{s}=0.042$. The mode of this distribution lay between $20 \mathrm{~s}$ and $25 \mathrm{~s}$. For distributions of similar quality $(\mathrm{s}<0.06)$, the mode was located between $20 \mathrm{~s}$ and $30 \mathrm{~s}$.

Similarly to the transient events, the histograms for the gas events indicated generally skewed right, unimodal distributions. The number of detected events ranged between 78 and 596 with a mode around $1 \mathrm{~h}$. $C_{v}$ varied between 0.43 and 0.77 , which indicated a periodic process irrespective of the trigger settings. Except for STA $=0.17 \mathrm{~h}(20 \mathrm{~min})$ and $\mathrm{STA}=0.25 \mathrm{~h}(15 \mathrm{~min})$ in combination with $\mathrm{LTA}=0.75 \mathrm{~h}$ and a threshold of 1.1 , the trigger settings yielded largely similar numbers of detected events, coefficients of variations and shapes of histograms. Regarding $\mathrm{STA}=600 \mathrm{~s}$, one should bear in mind that this interval contained effectively only 1-2 real data points. Thus these catalogs were potentially strongly influenced by outliers in the data. Nevertheless, the resulting distributions were more or less identical to those obtained using longer STA windows. For further analysis, we chose the catalog mean averaging/threshold $=1.1 / \mathrm{STA}=1200 \mathrm{~s} / \mathrm{LTA}=3600$ since it lies at center of the ensemble.

The histogram of the VT interevent times yielded a strongly skewed-right, unimodal distribution. The $C_{v}=1.4$ indicated an exponential or power-law decay of interevent times. The number of detected events was 250 with a mean interevent time of $3096 \mathrm{~s}$.

We fitted different probability density functions to the interevent times of the final catalogs, normalized by their respective mean (Fig. 6). The best model was selected by the lowest AIC. The interevent times of transients and degassing events were best represented by a log-normal distribution, while those of the VT events could be equally well fitted by a Gamma or Weibull distribution. For the VT events, we also tried an exponential distribution, but found the fit to be substantially lower than for the distributions shown here. Parameters of the best-fitting models are indicated in Fig. 7 (for parameters of other distributions see Table 1 in the Supplements).

The distributions of both, the transient events from the crater and the gas events exhibited a very similar pattern with respect to the trigger settings, albeit on very different time scales. Similarly, the coefficients of variation of the interevent times indicated a periodic process for both types of events. In contrast, the interevent times of the VTs indicated random occurrence or occurrences clustered in time. The best-fitting probability density functions of crater and gas events were strikingly similar, especially in comparison to the VT events (Fig. 7). It should be noted however, that the two-sample KolmogorowSmirnow-Test which tests whether two samples come from the same distribution did not indicate similarity within a reasonable confidence level.

The Gamma distribution of the volcano-tectonic interevent times resembled the tectonic scaling function (Eq. 1) even though the parameters were not identical (Fig. 7). In 

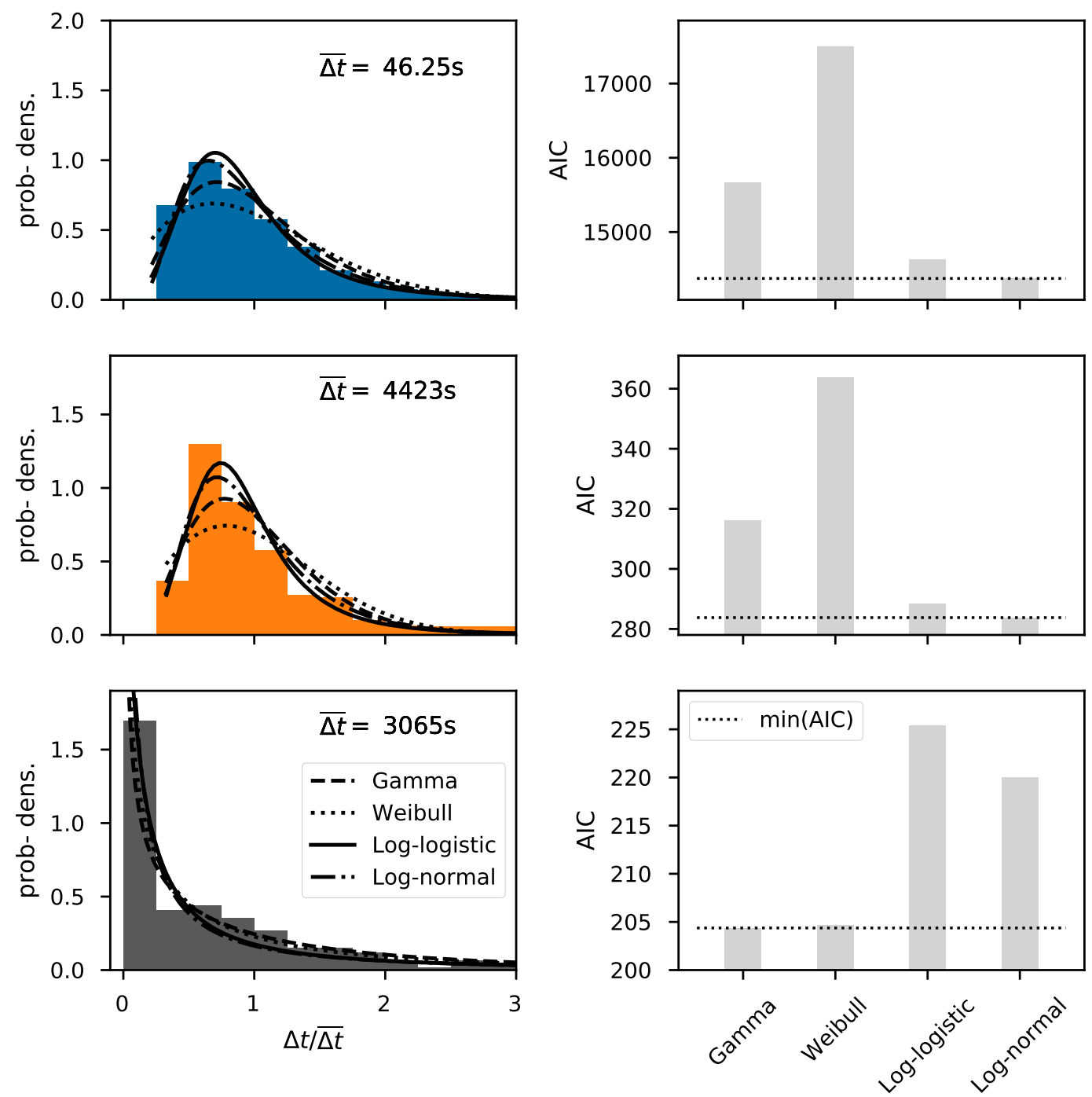

Figure 6. Left column shows histograms of interevent times, rescaled by the mean and different fitted probability distributions for transients (top row)), gas (middle) and VT events (bottom). Right column shows values of Akaike Information Criterium for each distribution. Lower AIC indicates better relative fit. 


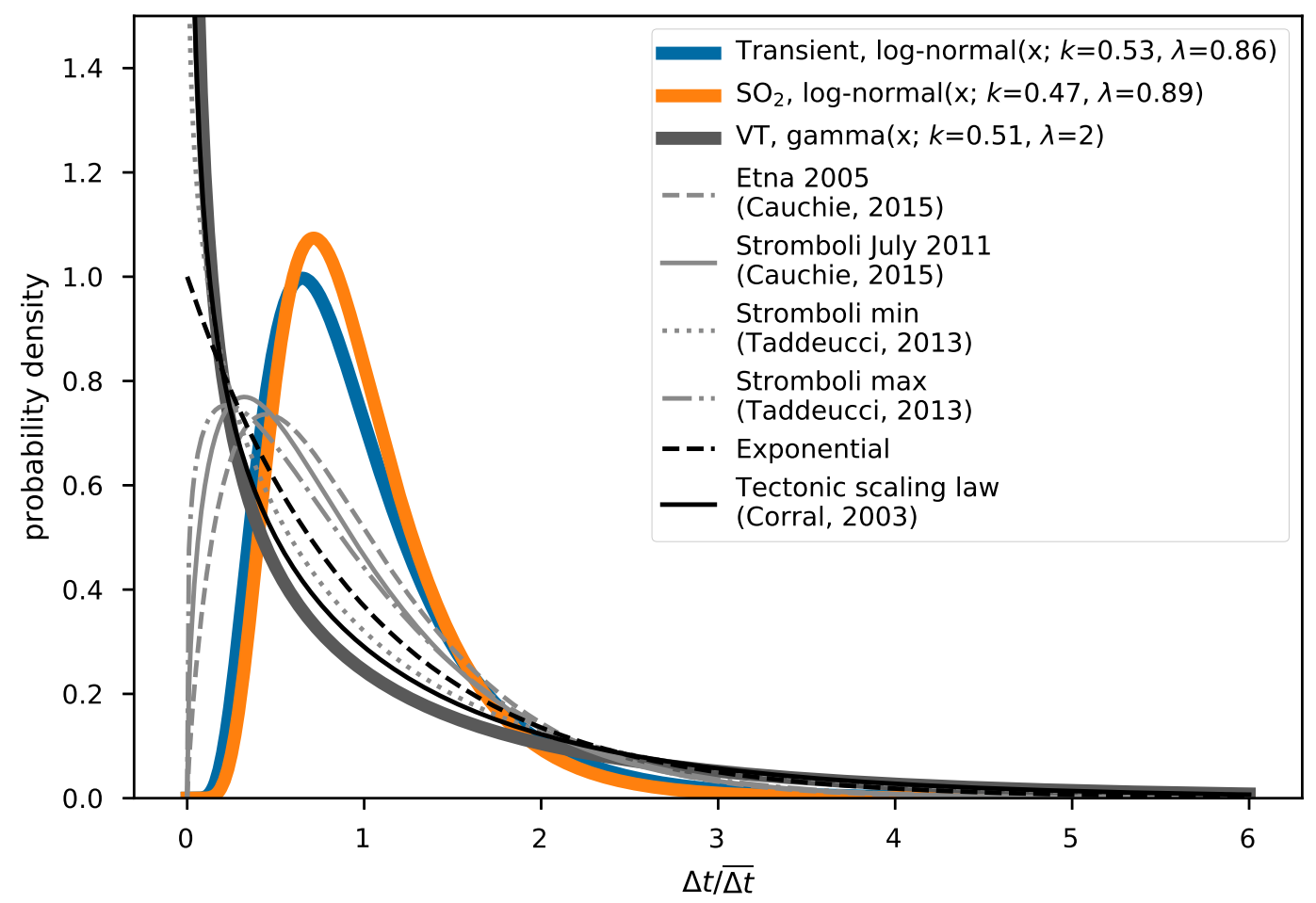

Figure 7. Rescaled interevent time distributions of transients, gas and VT events in comparison to other volcanoes. Interevent times are normalized by the respective mean. Distributions from literature are given in standardized form. 

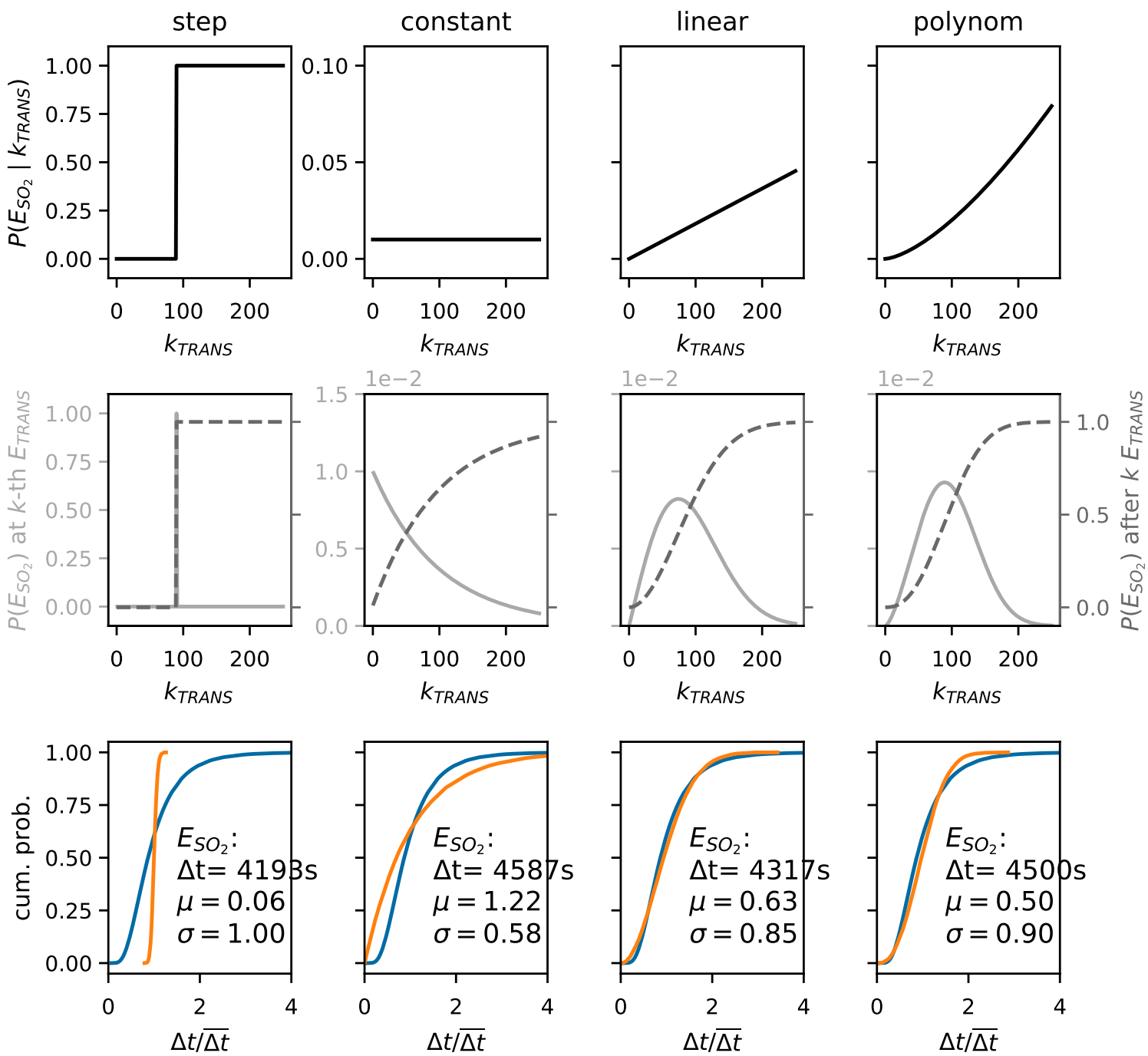

Figure 8. Coupled transient and degassing events as renewal process. top row: $p\left(E_{\mathrm{SO} 2}\right.$ $\left.n_{T R A}\right)$; middle: derived probabilities of degassing events at (solid, light gray lines) and after (dashed, dark gray lines) the $k$-th seismic transient since the last degassing; bottom: cumulative empirical distribution functions (EDF) of the rescaled interevent times of transients (blue) and degassing (orange). Columns correspond to the different scenarios of $p\left(E_{S O 2} \mid n_{T R A}\right)$

contrast, the transient and degassing events had little in common with the distributions found for long-period or explosive seismicity at other volcanoes, especially not with the frequently encountered exponential distribution.

\subsection{Statistical modeling}

The log-normal distribution of the interevent times of transients was used in the proposed statistical model (Algorithm 1) to generate artificial sequences of events. The parameters of the different functions for $p\left(E_{S O 2} \mid n_{T R A}\right)$ were adjusted manually to achieve a good agreement between the distributions of rescaled interevent times of transients and degassing. Fig. 8 summarizes the inputs and results. In the first scenario (step function), 


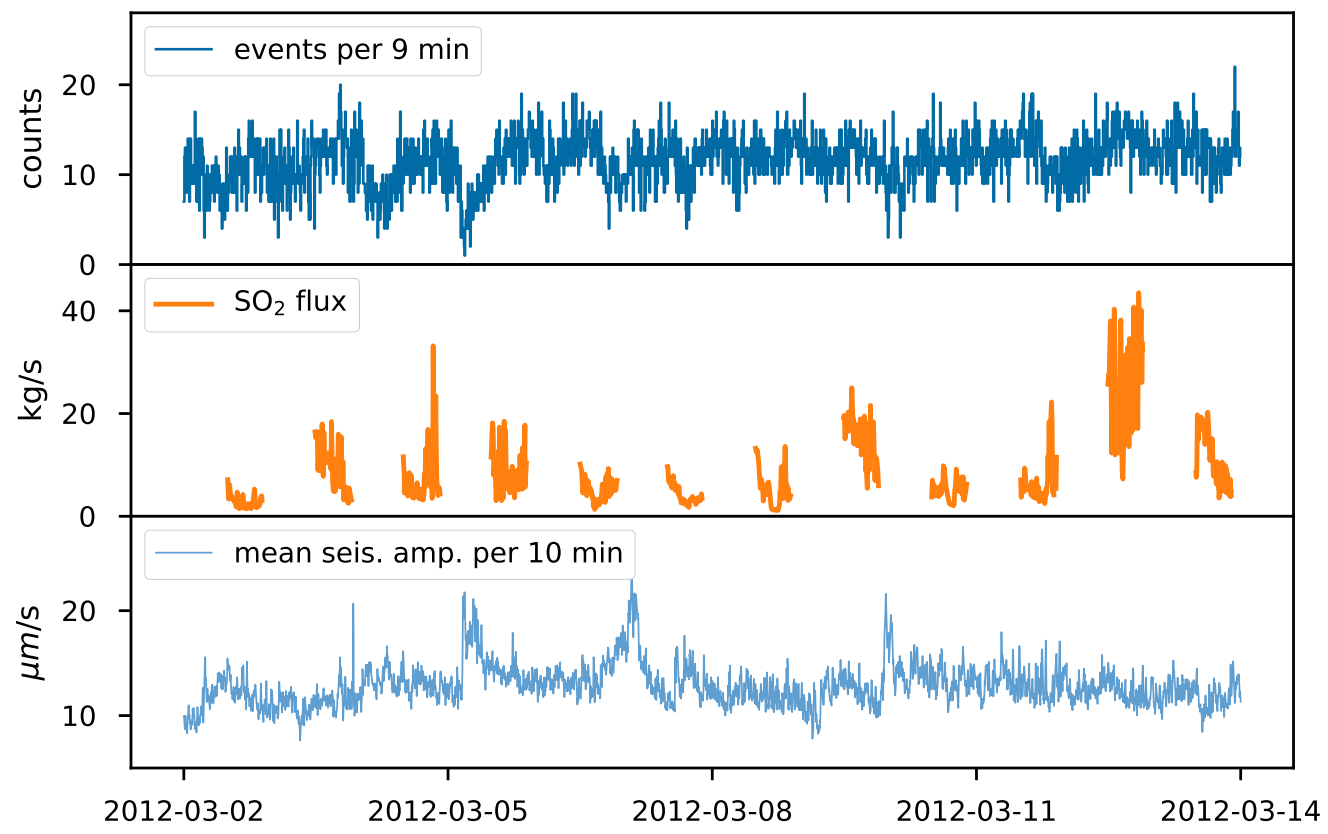

Figure 9. Time series of transients per consecutive 9-min interval, $\mathrm{SO}_{2}$ flux and mean seismic amplitude in 10-min intervals, shifted by $3 \mathrm{~min}$. Neither the seismic amplitude nor the amount of events per time correlate well with the degassing rate. Note, that the $\mathrm{SO}_{2}$ flux is interpolated from irregular, approximately 10-min intervals to regular 3-min intervals.

a gas event simply occurs after a fixed number of transients. Obviously, it failed to reproduce the targeted empirical distribution function (EDF). The second scenario - each transient triggers degassing with the same probability - also failed to reproduce an important feature of the targeted distribution, namely the inflection point. This was only achieved for an at least linear increase of the probability with the number of transients. Higher orders of increase then allowed an even finer tuning of the resulting EDF and a better match between the modeled and observed distributions.

In the model we assumed that the seismic signals are directly related to degassing activity. This gave rise to a new view on the correlation between the time series of degassing and seismicity: Instead of the amplitude, the number of events per time might correlate with the $\mathrm{SO}_{2}$ flux. However, the number of events per unit time clearly shows the same lack of correlation with the gas flux as the amplitude. (Fig. 9).

\section{Discussion}

\subsection{Event detection and catalog completeness}

The extreme variety of seismic waveforms resulting from the transients complicated the identification and detection of these events. Therefore, the transient catalog is almost certainly incomplete. In particular, events below the noise level can not be captured by the STA/LTA trigger. We considered the approach of Cauchie et al. (2015) who used template matching to detect weak events and improve their catalog. Unfortunately, this was impractical for our data set due to the huge number of different waveforms. For the same reason, a machine learning algorithm based on hidden Markov models (Hammer et al., 2012) failed. Bell et al. (2017) used manual picking to compile their catalog, which 
was firstly infeasible for our number of events and secondly limits the objectivity of the detection method. Nevertheless, we revised the VT catalog manually, but used a fixed set of rules to select the events which could have been implemented in the trigger algorithm. We explored the uncertainty of the transient and $\mathrm{SO}_{2}$ catalogs and its influence on the interevent time statistics by testing various combinations of trigger parameters. Despite the considerable differences, the various catalogs share one important characteristic, namely a periodic rather than random occurrence of events.

\subsection{Scale Invariance}

The rescaled distributions of interevent times of degassing and transients are surprisingly similar. Assuming, this similarity is real, the two observations could be the manifestations of a self-similar/scale-invariant process on different time scales. A possible link between them was demonstrated in the statistical experiment. However, it should be noted, that log-normal distributions are frequently found in natural processes and the ostensible similarity might be purely incidental.

\subsection{Interpretation as renewal process}

In our statistical experiment, we explored a possible relationship between seismicity and degassing based on very few, simple assumptions: the degassing activity is completely represented by the discrete seismic transients, and the probability of generating a gas peak depends solely on the number of transients since the last degassing event. Within this framework, we could show that, in order to meet the empirical observation, the probability of a degassing event needs to increase at least linearly with the number of seismic events.

\subsection{Seismicity as representative of active degassing}

As a consequence of the discretization, we neglected a possibly important part of information. In particular, the nature of the notorious seismic unrest at Villarrica is not well understood. While some parts of it are certainly codas from single events (Richardson \& Waite, 2013) interfering with each other and the normal background noise, others might be produced actively by continuous degassing processes and the convection of magma in the conduit (Palma et al., 2008; Ripepe et al., 2010). Fluid migration is known to cause sustained reverberations either in the magma column itself or of the conduit walls, which is observable as LP events or tremors (Chouet, 1996). Especially the latter were not targeted by the event detection. Similarly to the seismic unrest, the gas flux is continuous and the detected events should be regarded as variations, possibly superposed on a background level.

We proposed a possible link between degassing and seismicity, expressed as a probabilistic model. However the model does not indicate where or when the transition between the short time scales of the transient events and the longer times of the degassing variation takes place. The transients form the base of our model but unfortunately, their nature and origin is not very clear. Some authors generally describe the signals as explosions (Ortiz et al., 2003; Calder et al., 2004). Palma et al. (2008) claimed a good accordance with visible degassing processes at the surface of the lava lake (bubble bursting etc.). Goto and Johnson (2011) on the other hand reported a lack thereof, which indicates that these signals might also originate from deeper in the conduit. This would be more consistent with the results of Richardson and Waite (2013) who interpreted the moment tensor of a repetitive version of these waveforms as drag forces acting on the lava lake bottom.

We suggest two alternative concepts, what the nature of the transients implies for the degassing, illustrated in Fig. 10. If the signals originated solely at the free surface of 
a)
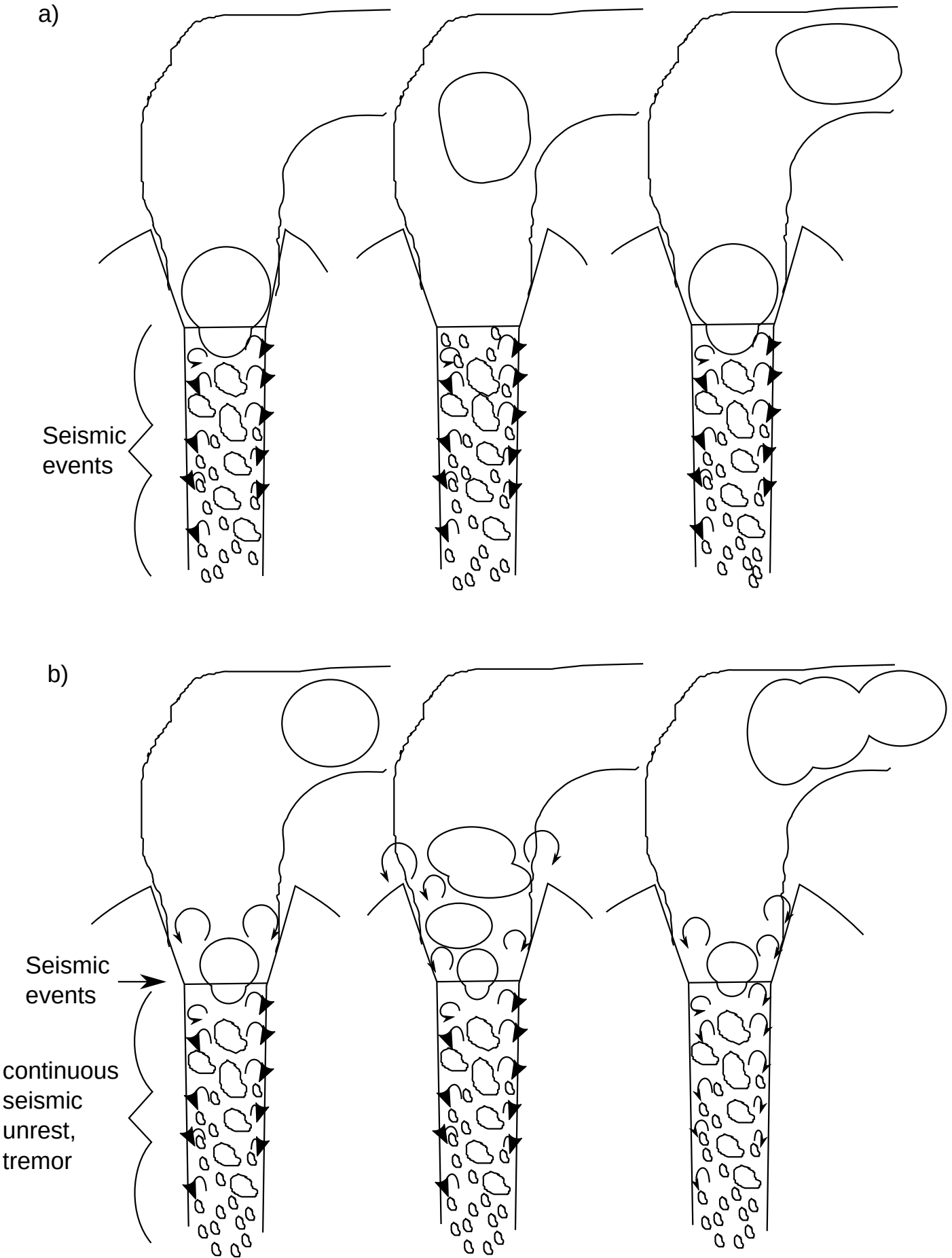

Figure 10. Two scenarios of where the transition between the time scales of the seismic events and the fluctuations of the degassing rate might occur: a) Seismic events originate from the whole conduit while gas accumulates into a slug that is released to form a temporary peak in the gas flux. b) Seismic events are produced solely by vigorous degassing (bubble/slug bursting) at the surface of the lava lake and gas fluctuations result from atmospheric mixing in the convectively rising portion of the plume. 
the lava lake (Model B) each event would indicate a new release of gas to the plume. In this case the transition between the time scales must be a result of mixing processes in the atmosphere and plume dynamics. If however transients could also be produced at some depth (Model A), the same gas unit (slug, bubble) could cause several seismic events during its ascent through the conduit. Then, the transition would rather be a result of the degassing and transport of the magma, even though additional atmospheric processes can not be ruled out.

In both cases we assume that the seismicity is predominantly an expression of the magmatic degassing. In any case the gas needs to accumulate somewhere to form the observed long-term fluctuations unless we assume varying supply of gas at depth as a third option. In principle, more gas could mean either more or bigger events. In the former case the number of events should be consistent with the gas flux while in the latter case it should be the seismic amplitude. However, neither is the case, which is why we discarded this third option.

The results of Liu et al. (2019) support Model B for two reasons: 1) It revealed periods of 30-50 s - comparable to the mean interevent times of the transients - in close proximity to the lake surface. This could be seen as indication that bubble bursts occur at this rate at the surface and our transients may be the seismic expression of that. 2) They report a significant difference to the periodicity recorded by the only slightly more distant station at the crater rim which they explain by atmospheric turbulences (suppl. Fig.S5). In contrast, our DOAS instrument measured the plume several kilometers away from the vent, leaving plenty of time and space for reorganization and homogenization of the juvenile plume and overprinting of early periodicities due to discrete gas releases. However, we can not exclude a deeper origin of at least some of the seismic events, which should be the case for Model A.

\subsection{Comparison to other volcanoes and earthquakes}

The enigmatic nature of the transient events only allows for limited comparison with other studies. These usually address a very specific volcanic activity (e.g. Vulcanian/Strombolian explosions) and it is unclear, whether other activity and smaller events were not present or were excluded from the analysis.

Erebus, similar to Villarrica, possesses an active lava lake. Varley et al. (2006) studied explosions related to bubble bursting in the lake, which occurred clustered in time. Their period of observation was several months compared to our merely two weeks. Villarrica was quite active during this time. Including periods of less activity might result in a more clustered occurrence.

Palma et al. (2008) suggested that discrete bubble bursting at Villarricas lava lake forms a continuum with Strombolian explosions. The latter, in their well-known form as spectacular, meters high ejections of magma, are rare at Villarrica. Less impressive bubble bursting however seems to be a plausible cause for the transients and therefore their occurrence may be comparable to that of Strombolian explosions. At Erebus and Stromboli, these were found to generally occur at random, resulting in an exponential distribution of their interevent times (Table 1). Our study revealed a clearly periodic occurrence of the transient events. To our knowledge, this has been reported only for short periods of high, unusual activity at other volcanoes. Assuming that Villarrica behaves in a similar way and that the transient events are comparable to Strombolian explosions, the log-normally distributed interevent times found in this study would indicate a period of unusual activity. Indeed, the volcano was observed to be relatively active during that time, producing several small ash eruptions and mild Strombolian activity (Fig. S6) in March 2012 (Global Volcanism Program, 2014). 
One of the most striking results is the clear difference between the rescaled interevent times of transients and VTs. VTs generally seem to obey the same Gamma-distribution as normal tectonic earthquakes. The only exception was reported by Traversa and Grasso (2010) for Etna, where the interevent time distribution significantly changed during two dyke intrusions. The VTs at Villarrica behave more or less as expected from the scaling law. The deviation in the parameters of the Gamma distribution might be related to the relatively low number of earthquakes in the catalog and false or missed detections. Alternatively, it could be the result of a magma intrusion similar to the case at Etna.

\subsection{Further remarks}

A more detailed picture might arise if amplitudes were included in the model. Nevertheless, we think, that this simplistic renewal process model provides an interesting new aspect on the relation between degassing processes and seismic activity at volcanoes. Moreover, variations on much larger (days, months) or smaller (minutes, seconds) time scales are possible but were not investigated here. Finally, it should be noted that the our seismic observations covered a much shorter period than the gas data and that we extrapolated the statistical results to the remaining period of gas observations. We think this is justified because OVDAS reported unchanging numbers of detected VTs and transients (LPs in their terminology) for January-April 2012.

\section{Conclusions}

We found periodic recurrences of seismic transients and peaks in the $\mathrm{SO}_{2}$ flux rate at Villarrica volcano based on the coefficient of variation of the interevent times. The modes of the distribution were at $24 \mathrm{~s}$ for the transients and $2160 \mathrm{~s}$ for the degassing events. In contrast, volcano-tectonic events showed the time-clustered occurrence expected for shear fractures with a mode at $0 \mathrm{~s}$ and a mean interevent time of $3065 \mathrm{~s}$. The normalized distribution functions of interevent times between transients and degassing events are remarkably similar, even though the events occurred on very different time scales. Provided seismic events and variations in $\mathrm{SO}_{2}$ flux are part of the same process, this suggests some sort of scale-invariance or self-similarity of the underlying time distributions. In regard to the general lack of convincing correlations between seismic amplitude and degassing rates, we suggest the analysis of interevent times as an interesting alternative way to link degassing and seismicity. The proposed renewal model reproduces the empirical observation very well, although it can not explain where the transition between the two time scales physically happens. In that respect, the nature of the seismic events requires more investigation. Simultaneous visual observations of the activity at the lake surface and measurements at higher time-resolution and closer to the conduit of the gas flux could further elucidate their role in the degassing process. Still, the discovered empirical statistical distributions and model provide a benchmark that future physical models of the degassing process need to meet.

\section{Acknowledgments}

The seismic campaign was funded by the Deutsche Forschungsgemeinschaft Collaborative Research Center CRC574. The seismometers were provided by the Geophysical Instrument Pool Potsdam (GIPP) of the Deutsches Geoforschungszentrum Potsdam (GFZ). The data are available through the GFZ Data Services (http://doi.org/10.5880/GIPP.201202.1). The $\mathrm{SO}_{2}$ flux data as well as the event catalogs are provided as Supporting Material. Data analysis and visualization was realized by means of Python (notably Obspy, Numpy, Scipy, Matplotlib, and Jupyter) and Generic Mapping Tools (GMT). We thank the numerous developers for providing of these APIs. 


\section{References}

Aiuppa, A., Bitetto, M., Francofonte, V., Velasquez, G., Parra, C. B., Giudice, G., .. Curtis, A. (2017, June). A CO2 -gas precursor to the march 2015 villarrica volcano eruption. Geochemistry, Geophysics, Geosystems, 18(6), 2120-2132. doi: $10.1002 / 2017 \mathrm{gc006892}$

Akaike, H. (1974, December). A new look at the statistical model identification. IEEE Transactions on Automatic Control, 19(6), 716-723. doi: 10.1109/tac .1974 .1100705

Bak, P., Christensen, K., Danon, L., \& Scanlon, T. (2002, April). Unified scaling law for earthquakes. Phys. Rev. Lett., 88, 178501. Retrieved from https://link .aps.org/doi/10.1103/PhysRevLett.88.178501 doi: 10.1103/PhysRevLett .88 .178501

Bell, A. F., Hernandez, S., Gaunt, H. E., Mothes, P., Ruiz, M., Sierra, D., \& Aguaiza, S. (2017, October). The rise and fall of periodic drumbeat seismicity at Tungurahua volcano, Ecuador. Earth and Planetary Science Letters, 475, 58-70. Retrieved 2018-04-19, from http://www.sciencedirect.com/ science/article/pii/S0012821X17304144 doi: 10.1016/j.epsl.2017.07.030

Bell, A. F., Mark, N., Stephen, H., Main, I. G., Gaunt, H. E., Patricia, M., \& Mario, R. (2018, February). Volcanic Eruption Forecasts From Accelerating Rates of Drumbeat LongPeriod Earthquakes. Geophysical Research Letters, 45(3), 1339-1348. Retrieved 2018-04-19, from https:// agupubs.onlinelibrary.wiley.com/doi/abs/10.1002/2017GL076429 doi: https://doi.org/10.1002/2017GL076429

Bottiglieri, M., Godano, C., \& D'Auria, L. (2009, October). Distribution of volcanic earthquake recurrence intervals. Journal of Geophysical Research: Solid Earth, 114(B10), B10309. Retrieved 2018-02-13, from http://onlinelibrary.wiley .com/doi/10.1029/2008JB005942/abstract doi: 10.1029/2008JB005942

Bottiglieri, M., Martino, S. D., Falanga, M., Godano, C., \& Palo, M. (2005, November). Statistics of inter-time of Strombolian explosion-quakes. Europhysics Letters (EPL), 72(3), 493-498. doi: 10.1209/epl/i2005-10258-0

Bredemeyer, S., \& Hansteen, T. H. (2014). Synchronous degassing patterns of the neighbouring volcanoes Llaima, and Villarrica in south-central Chile: the influence of tidal, forces. International Journal of Earth Sciences, 103(7), 1999-2012. Retrieved from http://dx.doi.org/10.1007/s00531-014-1029-2 doi: 10.1007/s00531-014-1029-2

Calder, E. S., Harris, A. J. L., Peña, P., Pilger, E., Flynn, L. P., Fuentealba, G., \& Moreno, H. (2004). Combined thermal and seismic analysis of the villarrica volcano lava lake, chile. Revista geológica de Chile, 31(2), 259272. Retrieved from http://www.scielo.cl/scielo.php?pid=S0716 -02082004000200005\&script=sci_arttext doi: http://dx.doi.org/10.4067/ S0716-02082004000200005

Cauchie, L., Saccorotti, G., \& Bean, C. J. (2015, September). Amplitude and recurrence time analysis of LP activity at Mount Etna, Italy. Journal of Geophysical Research: Solid Earth, 120(9), 2015JB011897. Retrieved 2017-09-29, from http://onlinelibrary .wiley.com/doi/10.1002/2015JB011897/abstract doi: 10.1002/2015JB011897

Chouet, B. (1996). Long-period volcano seismicity: its source and use in eruption forecasting. Nature, $380(6572), 309-316$.

Corral, A. (2003, September). Local distributions and rate fluctuations in a unified scaling law for earthquakes. Phys. Rev. E, 68, 035102. Retrieved from https://link.aps.org/doi/10.1103/PhysRevE.68.035102 doi: 10.1103/PhysRevE.68.035102

Daley, D. J., \& Vere-Jones, D. (2003). An introduction to the theory of point processes. Springer-Verlag. Retrieved from https://www.springer.com/de/ book/9780387955414 doi: 10.1007/b97277 
Davidsen, J., \& Kwiatek, G. (2013, February). Earthquake interevent time distribution for induced micro-, nano-, and picoseismicity. Physical Review Letters, 110(6). doi: 10.1103/physrevlett.110.068501

Davidsen, J., Stanchits, S., \& Dresen, G. (2007, March). Scaling and universality in rock fracture. Physical Review Letters, 98(12). doi: 10.1103/physrevlett.98 .125502

de Arcangelis, L., Godano, C., Grasso, J. R., \& Lippiello, E. (2016, April). Statistical physics approach to earthquake occurrence and forecasting. Physics Reports, 628, 1-91. doi: 10.1016/j.physrep.2016.03.002

De Lauro, E., De Martino, S., Falanga, M., \& Palo, M. (2009, October). Modelling the macroscopic behavior of Strombolian explosions at Erebus volcano. Physics of the Earth and Planetary Interiors, 176(3-4), 174-186. doi: https://doi.org/ 10.1016/j.pepi.2009.05.003

Dzierma, Y., \& Wehrmann, H. (2010). Eruption time series statistically examined: Probabilities of future, eruptions at Villarrica and Llaima Volcanoes, Southern Volcanic, Zone, Chile. Journal of Volcanology and Geothermal Research, 193(1), 82-92.

Endo, E. T., \& Murray, T. (1991, September). Real-time Seismic Amplitude Measurement (RSAM): a volcano monitoring and prediction tool. Bulletin of Volcanology, 53(7), 533-545. doi: 10.1007/bf00298154

Galle, B., Johansson, M., Rivera, C., Zhang, Y., Kihlman, M., Kern, C., ... Hidalgo, S. (2010, March). Network for Observation of Volcanic and Atmospheric Change (NOVAC) - A global network for volcanic gas monitoring: Network layout and instrument description. Journal of Geophysical Research, 115(D5). doi: $10.1029 / 2009 j \mathrm{j} 011823$

Global Volcanism Program. (2013). Villarrica. In E. Venzke (Ed.), Volcanoes of the World, v. 4.4.1. http://dx.doi.org/10.5479/si.GVP.VOTW4-2013: Smithonian Institution. Retrieved from http://dx.doi.org/10.5479/si.GVP.VOTW4-2013 (Downloaded 20 Nov 2015)

Global Volcanism Program. (2014). Report on Villarrica (Chile). Bulletin of the Global Volcanism Network, 39(3). doi: 10.5479/si.gvp.bgvn201403-357120

Goto, A., \& Johnson, J. B. (2011, March). Monotonic infrasound and Helmholtz resonance at Volcan Villarrica (Chile). Geophysical Research Letters, 38(6), L06301. Retrieved 2017-08-22, from http://onlinelibrary.wiley.com/doi/ 10.1029/2011GL046858/abstract doi: 10.1029/2011GL046858

Grainger, J. F., \& Ring, J. (1962, February). Anomalous Fraunhofer Line Profiles. Nature, 193(4817), 762-762. doi: 10.1038/193762a0

Gurioli, L., Harris, A. J. L., Houghton, B. F., Polacci, M., \& Ripepe, M. (2008, August). Textural and geophysical characterization of explosive basaltic activity at Villarrica volcano. Journal of Geophysical Research: Solid Earth, 113(B8), B08206. Retrieved 2017-08-22, from http://onlinelibrary.wiley.com/doi/ 10.1029/2007JB005328/abstract doi: 10.1029/2007JB005328

Hammer, C., Ohrnberger, M., \& Fh, D. (2012, November). Classifying seismic waveforms from scratch: a case study in the alpine environment. Geophysical Journal International, 192(1), 425-439. doi: 10.1093/gji/ggs036

Ignatieva, A., Bell, A. F., \& Worton, B. J. (2018). Point process models for quasiperiodic volcanic earthquakes. Retrieved from https://arxiv.org/pdf/1803 .07688.pdf

Jochen Stutz, U. P. (2008). Differential Optical Absorption Spectroscopy. SpringerVerlag GmbH. Retrieved from https://www.ebook.de/de/product/ 8900321/jochen_stutz_ulrich_platt_differential_optical_absorption -spectroscopy.html

Johansson, M., Galle, B., Zhang, Y., Rivera, C., Chen, D., \& Wyser, K. (2009, January). The dual-beam mini-DOAS technique - measurements of volcanic gas emission, plume height and plume speed with a single instrument. Bulletin of 
Volcanology, 71(7), 747-751. doi: 10.1007/s00445-008-0260-8

la Cruz-Reyna, S. D. (1991, December). Poisson-distributed patterns of explosive eruptive activity. Bulletin of Volcanology, 54(1), 57-67. doi: $10.1007 /$ bf00278206

Lehr, J., Eckel, F., Thorwart, M., \& Rabbel, W. (2019, November). Low-frequency seismicity at villarrica volcano: Source location and seismic velocities. Journal of Geophysical Research: Solid Earth, 124(11), 11505-11530. doi: 10.1029/ 2018jb017023

Liu, E. J., Wood, K., Mason, E., Edmonds, M., Aiuppa, A., Giudice, G., .. Bucarey, C. (2019, February). Dynamics of outgassing and plume transport revealed by proximal unmanned aerial system (UAS) measurements at volcán villarrica, chile. Geochemistry, Geophysics, Geosystems, 20(2), 730-750. doi: 10.1029/2018gc007692

Martino, S. D., Errico, A., Palo, M., \& Cimini, G. B. (2012, March). Explosion swarms at Stromboli volcano: a proxy for nonequilibrium conditions in the shallow plumbing system. n/a-n/a. doi: 10.1029/2011gc003949

Marzocchi, W., \& Bebbington, M. S. (2012, July). Probabilistic eruption forecasting at short and long time scales. Bulletin of Volcanology, 74(8), 1777-1805. doi: 10.1007/s00445-012-0633-x

Mather, T. A., Tsanev, V. I., Pyle, D. M., McGonigle, A. J. S., Oppenheimer, C., \& Allen, A. G. (2004, November). Characterization and evolution of tropospheric plumes from Lascar and Villarrica volcanoes, Chile. Journal of Geophysical Research: Atmospheres, 109 (D21), n/a-n/a. doi: 10.1029/2004jd004934

Matoza, R. S., \& Chouet, B. A. (2010, December). Subevents of long-period seismicity: Implications for hydrothermal dynamics during the 20042008 eruption of Mount St. Helens. Journal of Geophysical Research: Solid Earth, 115(B12), B12206. Retrieved 2017-09-29, from http://onlinelibrary.wiley.com/doi/ 10.1029/2010JB007839/abstract doi: 10.1029/2010JB007839

Molchan, G. (2005, June). Interevent Time Distribution in Seismicity: A Theoretical Approach. $\quad$ pure and applied geophysics, 162(6-7), 1135-1150. Retrieved 2017-10-02, from https://link. springer.com/article/10.1007/ s00024-004-2664-5 doi: 10.1007/s00024-004-2664-5

Mora-Stock, C. (2015). Seismic Structure and Seismicity of the Villarrica Volcano, (Southern Central Chile) (Phd Thesis, Christian-AlbrechtsUniversität zu Kiel). Retrieved from http://macau.uni-kiel.de/receive/ dissertation_diss_00017649

Moussallam, Y., Bani, P., Curtis, A., Barnie, T., Moussallam, M., Peters, N., ... Cardona, C. (2016, November). Sustaining persistent lava lakes: Observations from high-resolution gas measurements at Villarrica volcano, Chile. Earth and Planetary Science Letters, 454, 237-247. doi: 10.1016/j.epsl.2016.09.012

Ortiz, R., Moreno, H., García, A., Fuentealba, G., Astiz, M., Peña, P., ... Tárraga, M. (2003). Villarrica volcano (Chile): characteristics of the volcanic tremor, and forecasting of small explosions by means of a material failure, method. Journal of Volcanology and Geothermal Research, 128(1), 247-259. Retrieved from https://www.sciencedirect.com/science/article/pii/ S0377027303002580 doi: https://doi.org/10.1016/S0377-0273(03)00258-0

Palma, J. L., Blake, S., \& Calder, E. S. (2011, November). Constraints on the rates of degassing and convection in basaltic open-vent volcanoes. Geochemistry, Geophysics, Geosystems, 12(11), n/a-n/a. doi: 10.1029/2011gc003715

Palma, J. L., Calder, E. S., Basualto, D., Blake, S., \& Rothery, D. A. $\quad$ (2008, October). Correlations between $\mathrm{SO} 2$ flux, seismicity, and outgassing activity at the open vent of Villarrica volcano, Chile. Journal of Geophysical Research: Solid Earth, 113(B10), B10201. Retrieved 2017-08-25, from http://onlinelibrary.wiley.com/doi/10.1029/2008JB005577/abstract 
doi: 10.1029/2008JB005577

Pering, T. D., Tamburello, G., McGonigle, A. J. S., Aiuppa, A., James, M. R., Lane, S. J., ... Patanè, D. (2015, July). Dynamics of mild strombolian activity on Mt. Etna. Journal of Volcanology and Geothermal Research, 300, 103-111. doi: 10.1016/j.jvolgeores.2014.12.013

Platt, U., Bobrowski, N., \& Butz, A. ～(2018, January). Ground- Based Remote Sensing and Imaging of Volcanic Gases and Quantitative Determination of Multi-Species Emission Fluxes. Geosciences, 8(2), $44 . \quad$ doi: $10.3390 /$ geosciences 8020044

Rabbel, W., \& Thorwart, M. (2019). Villarrica Tomography (VITO) (Dataset). GFZ Data Services. doi: http://doi.org/10.5880/GIPP.201202.1

Richardson, J. P., \& Waite, G. P. (2013). Waveform inversion of shallow repetitive long period events at Villarrica, Volcano, Chile. Journal of Geophysical Research: Solid Earth, 118(9), 4922-4936. Retrieved from http://onlinelibrary.wiley.com/doi/10.1002/jgrb.50354/full doi: https://doi.org/10.1002/jgrb.50354

Richardson, J. P., Waite, G. P., \& Palma, J. L. (2014). Varying seismic-acoustic properties of the fluctuating lava lake, at Villarrica Volcano, Chile. Journal of Geophysical Research: Solid Earth, 119(7), 5560-5573. Retrieved from https://agupubs .onlinelibrary.wiley.com/doi/10.1002/2014JB011002 doi: https://doi.org/10.1002/2014JB011002

Ripepe, M., \& Marchetti, E. (2002, November). Array tracking of infrasonic sources at Stromboli volcano. Geophysical Research Letters, 29(22), 33-1. Retrieved 2018-04-25, from https://agupubs.onlinelibrary.wiley.com/doi/full/ 10.1029/2002GL015452 doi: 10.1029/2002GL015452

Ripepe, M., Marchetti, E., Bonadonna, C., Harris, A. J. L., Pioli, L., \& Ulivieri, G. (2010, August). Monochromatic infrasonic tremor driven by persistent degassing and convection at Villarrica Volcano, Chile. Geophysical Research Letters, 37(15), L15303. Retrieved 2017-08-22, from http:// onlinelibrary.wiley.com/doi/10.1029/2010GL043516/abstract doi: 10.1029/2010GL043516

Saichev, A., \& Sornette, D. (2006, August). Universal distribution of interearthquake times explained. Physical Review Letters, 97(7). doi: 10.1103/physrevlett.97.078501

Salerno, G. G., Burton, M., Grazia, G. D., Caltabiano, T., \& Oppenheimer, C. (2018, oct). Coupling between magmatic degassing and volcanic tremor in basaltic volcanism. Frontiers in Earth Science, $6 . \quad$ doi: 10.3389/ feart.2018.00157

Sanchez, L., \& Shcherbakov, R. (2012, December). Temporal scaling of volcanic eruptions. Journal of Volcanology and Geothermal Research, 247-248, 115121. Retrieved 2018-03-15, from http://www.sciencedirect.com/science/ article/pii/S0377027312002429 doi: 10.1016/j.jvolgeores.2012.08.004

Taddeucci, J., Palladino, D. M., Sottili, G., Bernini, D., Andronico, D., \& Cristaldi, A. (2013, July). Linked frequency and intensity of persistent volcanic activity at stromboli (italy). Geophysical Research Letters, 40(13), 3384-3388. doi: $10.1002 /$ grl.50652

Touati, S., Naylor, M., \& Main, I. G. $\quad$ (2009, April). Origin and Nonuniversality of the Earthquake Interevent Time Distribution. Physical Review Letters, 102(16), 168501. Retrieved 2017-11-13, from https://link.aps.org/doi/ 10.1103/PhysRevLett.102.168501 doi: 10.1103/PhysRevLett.102.168501

Traversa, P., \& Grasso, J.-R. (2010, August). How is Volcano Seismicity Different from Tectonic Seismicity? Bulletin of the Seismological Society of America, 100(4), 1755-1769. Retrieved 2017-09-29, from https:// pubs.geoscienceworld.org/bssa/article/100/4/1755/349480/how-is -volcano-seismicity-different-from-tectonic doi: 10.1785/0120090214 
Vandaele, A. C., Simon, P. C., Guilmot, J. M., Carleer, M., \& Colin, R.

(1994). SO2absorption cross section measurement in the UV using a Fourier transform spectrometer. Journal of Geophysical Research, 99(D12), 25599. doi: $10.1029 / 94 \mathrm{jd} 02187$

Varley, N., Johnson, J., Ruiz, M., Reyes, G., Martin, K., de Ciencias, F., \& Colima, M. (2006). Applying statistical analysis to understanding the dynamics of volcanic explosions. In Statistics in volcanology (Vol. 1, pp. 5776). Citeseer. Retrieved from http://citeseerx.ist.psu.edu/viewdoc/ download?doi=10.1.1.521.1265\&rep=rep1\&type=pdf

Voigt, S., Orphal, J., Bogumil, K., \& Burrows, J. P. （2001, October). The temperature dependence $(203-293 \mathrm{~K})$ of the absorption cross sections of O3 in the 230-850 nm region measured by Fourier-transform spectroscopy. Journal of Photochemistry and Photobiology A: Chemistry, 143(1), 1-9. doi: 10.1016/s1010-6030(01)00480-4

Witter, J. B., Kress, V. C., Delmelle, P., \& Stix, J. (2004, July). Volatile degassing, petrology, and magma dynamics of the Villarrica Lava Lake, Southern Chile. Journal of Volcanology and Geothermal Research, 134(4), 303-337. Retrieved 2017-08-25, from http://www.sciencedirect.com/science/article/pii/ S0377027304000630 doi: 10.1016/j.jvolgeores.2004.03.002 